\title{
Sex Differences in Memory and Other Cognitive Abilities
}

Catharina Lewin

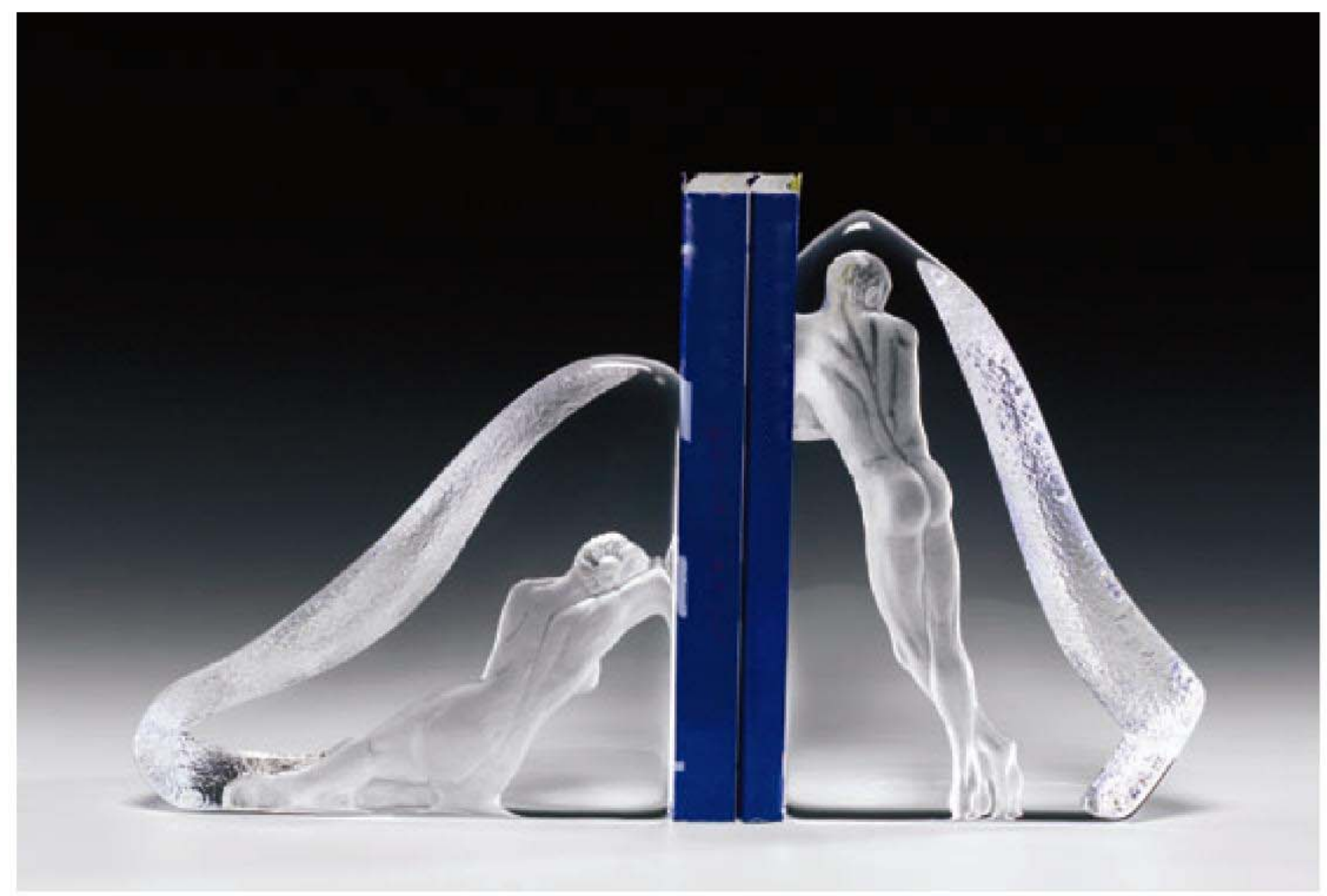

$$
\begin{aligned}
& \text { Separtment of Psychology } \\
& \text { Stockholm University }
\end{aligned}
$$


Cover photograph: "Adam and Eve". Design: Peter Nilsson. Reprinted with kind permission from Nybro Glasbruk AB

(C) 2003 Catharina Lewin ISBN 91-7265-634-4 Intellecta DocuSys AB, 2003 
Doctoral Dissertation, 2003

Department of Psychology

Stockholm University

S-106 91 Stockholm

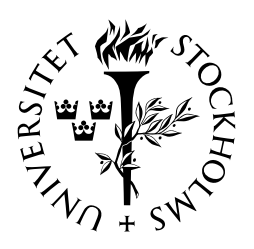

\begin{abstract}
The aim of the present thesis was to study sex differences in memory and other cognitive abilities in healthy adults. In Study I, participants performed a number of episodic memory tasks that were more or less verbal in nature. Results showed that women performed on a higher level than did men in the episodic memory tasks where it was possible to use verbal labels, whereas men performed on a higher level than did women in a visuospatial episodic memory task. In Study II, women's advantage in face recognition was investigated. Results showed that women performed at a higher level than did men only in the recognition of other women's faces. In Study III, sex differences in cognitive tasks as well as brain measures were investigated in healthy older adults. Results showed that only the sex differences in a motor task could, to some extent, be explained by sex differences in one of the brain measures. The findings, as well as possible explanations for these patterns of results, are discussed in a theoretical context.
\end{abstract}

Key words: cognition, memory, sex differences, gender, verbal abilities, visuospatial, face recognition, brain aging. 



\section{To "Mormor Britta"}

For touching, inspiring and supporting

whatever I have taken on in life. 


\section{Acknowledgements}

The road that I've traveled for the past four years has been long and winding and at times the finish line has been out of sight. As I now approach the end and look back, I wonder where I would be without the truly amazing support of many friends and colleagues.

First of all I want to express a heartfelt thank you to my Supervisor, Lars-Göran Nilsson, for sharing his expertise, for support and guidance, without which this thesis would not exist. Above all, thank you for taking me on!

Lars-Göran Öst deserves a big thank you for help and support when I needed it the most. I am indebted also to Jerker Rönnberg and Ola Svensson who reviewed an earlier version of this thesis and came with constructive comments that have improved this work.

Agneta Herlitz introduced me to psychological research and helped with initial funding, for this I am sincerely grateful. Maria Larsson, and everyone else in the Memory group at the department, thank you for many interesting seminars as well as support and feed-back.

Luki Hagen, thank you for putting up with my complaints and frustrations. I am not sure how, but you always managed to make me smile! Thanks also for many nice chats on the train!

Hedvig Söderlund, my co-author but also dear friend, for always being supportive and helping me finish this thesis - how can I ever thank you? Petra Lindfors, my friend and the one who could always answer any questions I had, thank you for always being there!

Mats Najström always made sure I took my coffee breaks and I thank you for that, but above all for being a true friend, for support and making me laugh when I thought that wasn't possible!

To all my friends in the Postgraduate Student's Union, especially to the two vice presidents during my time there - Johan Fallby and Sara 
Göransson - thank you all for your hard work in making the department a better place for all of us!

For touching my life and being a true inspiration to everyone she meets, I will never be able to express how grateful I am to my dear grandmother Britta. To my parents, Ulf and Elisabeth, who couldn't believe it when I started this journey, and who can't believe I will soon have completed it, thank you for being there and supporting me. And last but not least, Calle Uhlin, without whose love and support, I would have given up a long time ago. 



\section{List of Studies}

The present thesis is based on the following studies, which will be referred to in the text by their Roman numerals:

I. Lewin, C., Wolgers, G., \& Herlitz, A. (2001). Sex differences favoring women in verbal but not in visuospatial episodic memory. Neuropsychology, 15(2), 165-173.

Copyright (C) 2001 by the American Psychological Association. Reprinted with permission.

II. Lewin, C., \& Herlitz, A. (2002). Sex differences in face recognition - Women's faces make the difference. Brain and Cognition, 50(1), 121-128.

Copyright (2002), reprinted with permission from Elsevier.

III. Lewin, C., Söderlund, H., \& Nilsson, L.-G. (2003). Sex differences in cognitive abilities and brain changes in old age: Are they related? Manuscript submitted for publication. 


\section{Table of Contents}

General Introduction ............................................................. 1

Terminology: Sex or Gender? ................................................... 2

Sex Differences in Cognition ............................................................. 3

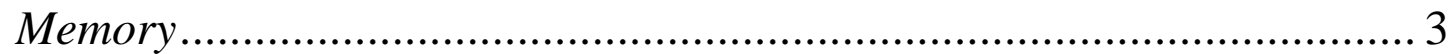

A Brief History ....................................................................... 3

The Processing View................................................................ 4

The Memory Systems View.................................................. 4

Short-term Memory and Working Memory ................................... 5

Procedural Memory ................................................................. 6

Perceptual Representation System .............................................6

Semantic Memory .......................................................... 7

Episodic Memory ......................................................... 8

Other Cognitive Abilities .............................................................. 13

Spatial Abilities ................................................................... 13

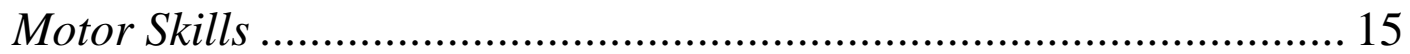

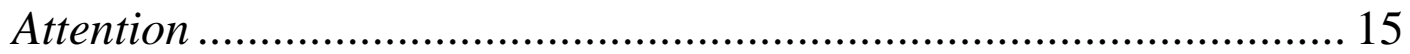

Cognition and the Brain ........................................................ 17

Cognition and Aging .................................................................. 19 


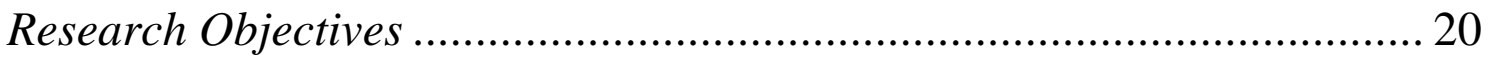

The Purpose of the Present Studies ................................................... 20

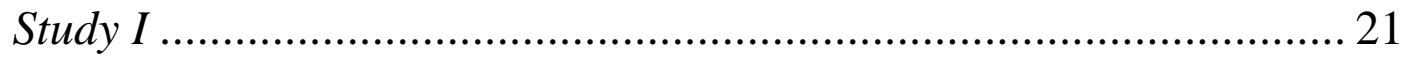

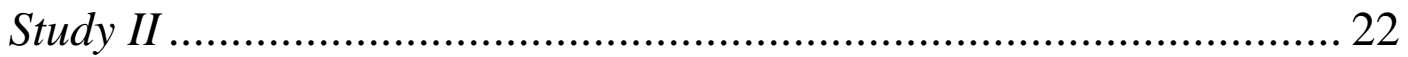

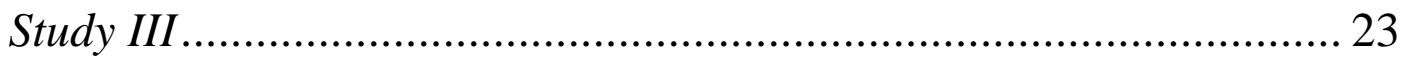

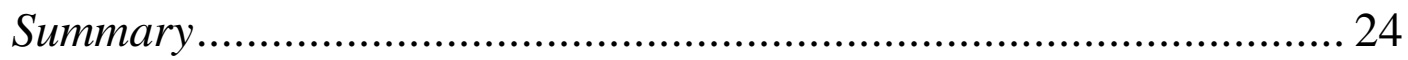

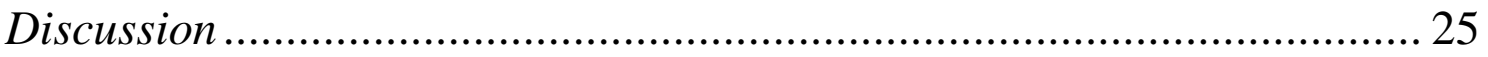

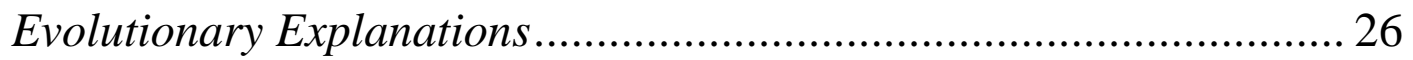

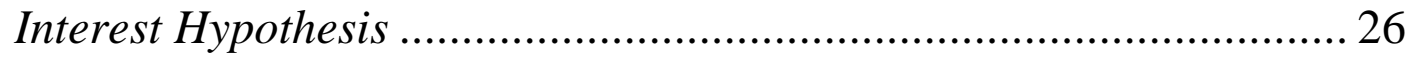

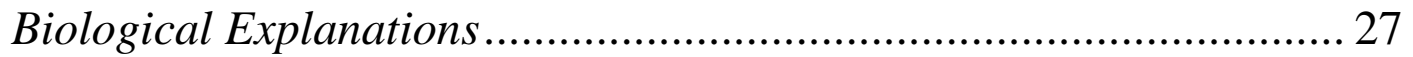

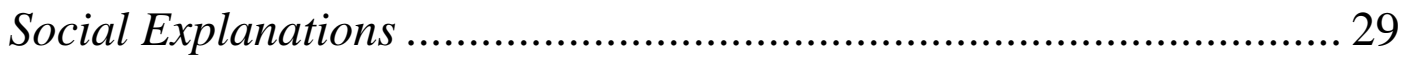

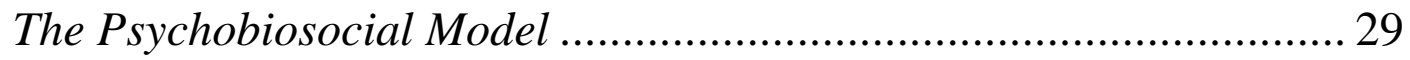

Changes in Cognitive Sex Differences Over Time.................................. 30

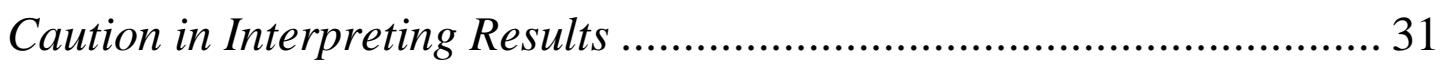

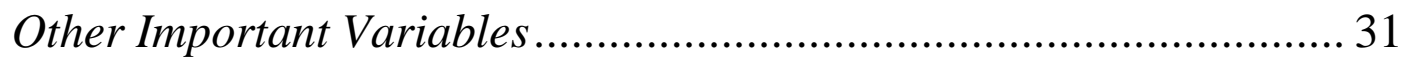

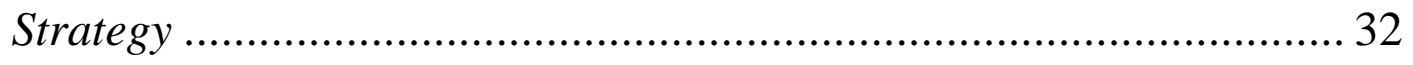

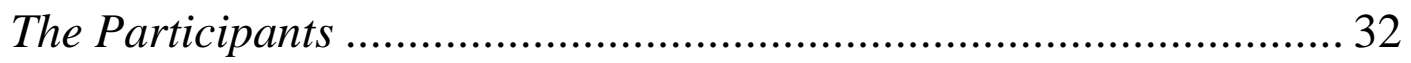

Studies on Sex Differences in Cognition............................................ 33

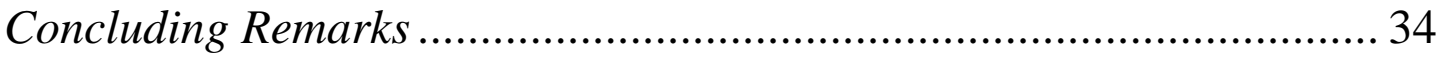

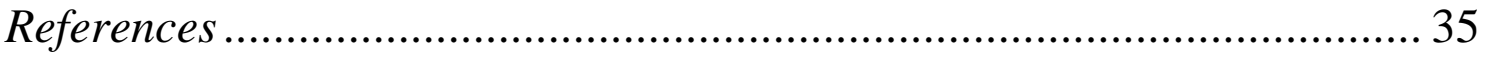





\section{General Introduction}

The present thesis examines sex differences in memory and other cognitive abilities in healthy adults. There has been a surge of research about sex differences in cognition since the highly influential work of Maccoby and Jacklin entitled "The psychology of sex differences" was published in 1974. This increase has been especially strong in the last ten to fifteen years.

This thesis is about cognition, and memory in particular. Cognition is a general term for different mental processes including thought, reasoning, understanding, perception, memory, decision making and problem solving. The term cognition derives from the Latin "cogitare", meaning "to think". Of the three studies included in this thesis, the first two concern sex differences in memory in young healthy adults, whereas the third examines sex differences in a variety of cognitive tasks and their relation to the aging brain. Other cognitive abilities are beyond the scope of the present thesis.

Most would likely agree that the primary way of classifying people into groups is on the basis of their sex, and that there are relatively obvious ways in which men and women differ, in addition to having much in common. The interest of the general public concerning topics about sex differences seems to be unlimited, judging from the vast amount of popular press on the topic sold every year.

So, why are we, the public, so interested in these differences? There are undoubtedly more between-sex similarities than differences, yet the differences receive more interest. Whatever the reason, the fact that men and women differ in various aspects raises the curiosity of the general public and researchers alike - what are these differences, how large are they and why do they exist?

There are some researchers who believe that studies of sex differences in cognition result in enforced stereotypes and increased discrimination and should therefore not be conducted or reported (e.g., Baumeister, 1988). However, a number of researchers disagree with this opinion and believe 
that this line of research is important (e.g., Eagly, 1990, 1994, 1995; Halpern, 2000). For instance, Halpern states that with this type of research it might also be possible to unravel myths regarding sex differences. It is also important to note that the existing differences are not necessarily deficiencies and that they can help us gain knowledge of how and why the brains of men and women work differently. It is also important to keep in mind that men and women, respectively, have the upper hand in different tasks. It is not the case that one sex is superior to the other in all cases. Once sex differences have been found, or the absence of sex differences has been confirmed, the cause or causes of these findings should be investigated. Thus, an important reason for studying sex differences in cognition is to learn more about brain and mind.

My personal belief is that valuable information can be gained in studying sex differences in cognition, most importantly with respect to how the brains of men and women work differently. With further research on differences and similarities in brain functioning, it might be possible to determine why boys and men are more prone to dyslexia (Miles, Haslum, $\&$ Wheeler, 1998), all levels of mental retardation (Drews, YearginAllsopp, Decoufle, \& Murphy, 1995) and some forms of mental illnesses, such as schizophrenia (e.g., Usall et al., 2001). In the early phases of research on sex differences in cognition, the results were perhaps of even greater importance - if it had been concluded that there were large sex differences in memory and other cognitive abilities, it might have warranted different kinds of teaching methods and training skills for boys and girls. Today, we know that although some differences exist they are not very large and do not warrant different training skills, and perhaps above all, that there are many individuals who do not fit the general pattern. This issue will be addressed further in the discussion section of this thesis.

\section{Terminology: Sex or Gender?}

The focus of this work is on differences between men and women in different aspects of cognition. There is disagreement among researchers as to the terminology - some prefer to use the word "gender" and others the word "sex". Originally, the word "sex" referred to the biological distinction, whereas the word "gender" referred to where the person belongs in regard to the society's social constructions and expectations. I believe (and as will be discussed elsewhere) that the differences between men and women are a result of a combination of their biological and 
social/environmental backgrounds, and that these two are strongly intertwined. I will use the term "sex" throughout this thesis, as individuals are initially affected by biology (e.g., prenatal hormones), before societal constructs can have any influence on them.

\section{Sex Differences in Cognition}

There are several different types of cognitive abilities, and the sex differences in these vary with respect to both direction and size. All tasks are not pure; that is, they may assess two or more abilities. For example, a task assessing motor skills may also tap working memory and/or visuospatial abilities, as these cognitive skills are needed or give an advantage when solving the task at hand. A summary of the findings of sex differences and similarities in different kinds of memory will be discussed first, followed by the findings in other cognitive tasks used, or related to those used in the present thesis (i.e., spatial abilities, motor skills, and attention).

\section{Memory}

"Memory is the glue that binds our mental life, the scaffolding that holds our personal history and that makes it possible to grow and change throughout life. When memory is lost, as in Alzheimer's disease, we lose the ability to recreate our past, and as a result we lose our connection with ourselves and with others." Squire and Kandel (1999, p. ix)

\section{A Brief History}

German psychologist Hermann Ebbinghaus became a pioneer in memory research, which evolved as a branch of philosophy, when he published $O n$ Memory in 1885. One of Ebbinghaus' findings was that some memories have a short life span (minutes) and others have a much longer life span, remaining for days or months (Squire \& Kandel, 1999). Also at the turn of last century, the American philosopher William James made a distinction between primary memory, which involved memories from seconds to 
minutes, and secondary memory ranging from hours to weeks, months or up to a lifetime (Squire \& Kandel, 1999). This distinction still holds today, although the terms most often used are short-term and long-term memory.

The structure and organization of memory has been vividly discussed and debated for decades, and there is still much unknown about how memory works, not least about how and where in the brain memories are processed and stored. The main issues today concern the question of memory being composed of a number of independent memory systems (the "memory systems view"), or a unitary system (the "processing view"). Both of these views have received ample support.

\section{The Processing View}

The processing view emphasizes differences in processing within a unitary memory system (e.g., Roediger, 1990; Blaxton, 1995). This view proposes transfer-appropriate processing, meaning that memory performance is enhanced when the same type of processing is used at study and test, and that the performance will drop if there is a mismatch in processing between study and test. The levels-of-processing framework, which also belongs to this view, entails that the deeper the processing stimuli are subject to, the easier recollection will be (Craik \& Lockhart, 1972).

\section{The Memory Systems View}

Apart from the distinction between short-term and long-term memory, there was no consensus regarding the structure of memory before 1972. It was more or less seen as one system with many different and relatively specific parts such as acquisition memory, active memory, short-term and very short-term memory (Tulving, 1972). As Tulving pointed out, there are often loose definitions and major concepts in new and immature sciences.

In 1972, however, Tulving proposed a structure for memory, which, although since modified (Nyberg \& Tulving, 1996; Tulving, 1983, 1985, 1993, 1999; Tulving \& Schacter 1990), has become widely accepted. This conceptualization claims that human memory can be divided into five memory systems. These systems are not independent but rather work together, and represent different types of memories from the most simple and general to the more specific. The five memory systems are: short-term memory, procedural memory, perceptual representation system, semantic memory and episodic memory. 


\section{Short-term Memory and Working Memory}

Following Hermann Ebbinghaus' and William James' distinction between short-term and long-term memory at the turn of the last century, a surge of research on short-term memory emerged around 1960. Broadbent (1958) proposed a model of attention, claiming that humans have a limited capacity for attention and thus must screen information in order to let the most important information come into awareness and disregard irrelevant information. Peterson and Peterson (1959) found that it was difficult to remember a few unrelated words for a very short period of time, even seconds, if distracted or asked to do another task simultaneously.

Atkinson and Shiffrin $(1968,1971)$ proposed that memory consisted of three memory stores. One consisted of sensory registers, information that was briefly heard or seen for a few seconds, before its traces decayed. The second consisted of stimuli that are given attention, identified and recoded and then entered into short-term memory (STM), which has a limited capacity. In order to learn, the stimulus must be consolidated in order to be transferred to long-term memory, which is the third memory store. The long-term memory is more durable than are the other two memory stores proposed by Atkinson and Shiffrin. Miller (1956) claimed that short-term memory could hold only seven items (plus or minus two), although items could be grouped together (chunked), in which case the limit of what could be retained would be seven chunks, plus or minus two. Thus, short-term memory is extremely vulnerable to distraction and decay.

Baddeley and Hitch (1974) had an alternative viewpoint. They suggested the term "working memory" for tasks when participants are required to maintain items in short-term memory while performing another task, such as reading, counting or problem solving (Baddeley, 1986). Thus, short-term memory can be seen as a passive store, whereas working memory involves storage and concurrent manipulation of information (Baddeley, 1986).

Herlitz, Nilsson, and Bäckman (1997) reported no sex differences in working memory tasks in a large sample of adults. Until very recently, there were few direct reports of sex differences in human working memory. However, Duff and Hampson (2001) somewhat surprisingly found sex differences favoring women in three spatial working memory tasks, independent of overall ability, perceptual speed or speed of verbal access. 
Duff and Hampson also found sex differences favoring women in a verbal working memory task.

One working memory task that has shown sex differences favoring women (e.g., Majeres, 1983) is the Digit Symbol subtest from the Wechsler Adult Intelligence Scales (WAIS) battery (Wechsler, 1981). Besides assessing working memory, this task also taps on perceptual and motor speed. In this task, the participant is given a code with digits and their corresponding symbols. With this in view, they are asked to, as quickly and accurately as possible, transform a number of symbols to the correct digit. Younger adults have been found to perform at a higher level in this task than do older adults (e.g., Joy, Fein, Kaplan, \& Freedman, 2000; Peretti, Danion, Gierski, \& Grangé, 2002). A modified version of this test is the Letter Digit Substitution task, which was used in Study III. In this task, letters are transformed into their corresponding digits.

Age-related decline in working memory has been found among both men and women (e.g., Janowsky, Chavez, \& Orwoll, 2000). However, the decline in performance with aging is smaller in short-term memory (which does not involve maintaining other information or conducting a concurrent task) than in working memory tasks (Verhaeghen, Macoen, \& Goosens, 1993). Thus, there is some evidence that older adults are more affected by interference effects than are younger adults (e.g., Hasher, Zacks, \& May, 1999).

\section{Procedural Memory}

Procedural memory deals with learning and knowing how to perform motor and cognitive skills (Schacter, Wagner, \& Buckner, 2000). How to zip a zipper, ride a bicycle or read are typical procedural memory skills, once these abilities have been mastered. It is an implicit memory system, meaning that these abilities are exhibited without consciously thinking of how they are performed. There is a very limited amount of literature on sex and age differences in procedural memory. However, there seems to be almost no age-related decline (e.g., Light \& La Voie, 1993) or sex differences (Mitchell, 1989) in procedural memory.

\section{Perceptual Representation System}

The perceptual representation system (PRS) is involved in identifying objects and words (Tulving \& Schacter, 1990). Instantly knowing, when 
seeing a telephone, that it is used to make calls, or knowing that a glass is used in drinking, is knowledge that belongs to the perceptual representation system. PRS is an implicit memory system, meaning that associations are not made consciously. Being an unconscious process, this memory can be referred to as "just knowing". However, as with all memories, the individual must have learned at some point to make the necessary associations. PRS is involved in priming. Priming involves the increasing ability to identify an object or a word as a result of prior exposure to the object or word (Schacter, 1987). For example, a participant is presented with the word "pineapple" and later given the letters "pi" and asked to say the first word that comes to mind. If the word "pineapple" is said, then this is believed to have been as a result of the previous presentation. There are no sex differences in priming (Herlitz et al., 1997), and small effects of age, with young adults performing at a higher level than do older adults, according to a meta-analysis by La Voie and Light (1994).

\section{Semantic Memory}

Semantic memory can be thought of as a mental dictionary or thesaurus. It handles the individual's knowledge of words, their meanings, relationships and referents, and deals with rules and formulas. It can be seen as our personal knowledge bank (Tulving, 1972). Knowing that Paris is the capital of France, or where you were born, is information belonging to the semantic memory.

Semantic memory can be tested with several different types of tests, those tapping verbal abilities apparently the most common. In fluency tasks, participants are asked to generate as many words as possible in a limited amount of time starting with a given letter (phonological fluency) or belonging to a semantic category, such as 'animals', 'fruits' or 'tools' (semantic fluency). It has been shown that semantic and phonological fluency are affected differently by disease - phonological fluency is more sensitive to lesions of the frontal lobe and semantic fluency is more impaired in Alzheimer's disease (Troyer, Moscovitch, Winocur, Leach, \& Freedman, 1998; Pendleton, Heaton, Lehman, \& Hulihan, 1982). Phonological fluency demands a higher degree of attention, whereas semantic fluency is more demanding on the semantic system (which is impaired in Alzheimer's disease). 
In phonological fluency tasks, women often perform at a higher level than do men, although the differences are usually quite small (e.g., Crossley, D'Arcy, \& Rawson, 1997; Herlitz, Airaksinen, \& Nordström, 1999). In semantic fluency tasks, the size and direction of the sex differences seems to vary with the category. Men have been found to perform at a higher level than do women when asked to name tools, whereas women have the advantage in naming fruits (Capitani, Laiacona, \& Barbarotto, 1999). In naming animals, no sex differences have been found (e.g., Acevado et al., 2000; Bolla, Gray, Resnick, Galane, \& Kawas, 1998). An effect of men's and women's different interests could account for this pattern of results. It could be the case that men have a larger vocabulary for tools and, although women might be slightly more familiar with fruits, there could be doubt as to whether this would account for women's superiority in naming fruits.

Fluency tasks are often used in tests of neuropsychological assessment, as they are helpful in diagnosing things such as different forms of dementia (e.g., Pasquier, Lebert, Grymonprez, \& Petit, 1995). Fluency tasks seem to be affected by several factors, including educational attainment with more educated participants performing at a higher level (Crossley et al., 1997), verbal intellectual ability (Bolla et al., 1998) and depression (see King \& Caine, 1990). In regard to age, younger participants perform at a higher level than do older participants (Crossley et al., 1997; Kempler, Teng, Dick, Taussig, \& Davis, 1998; Tomer \& Levin, 1993), although one largesample study (Bäckman \& Nilsson, 1996) found that between the ages of 35 and 50 years there was a stability in performance, but noted a gradual decline among the older (aged 55 to 80 years).

\section{Episodic Memory}

Episodic memory is the most personal of the memory systems as it involves memories that are personally related and have both a setting and a time (Tulving, 1972). All autobiographical memories therefore belong to the episodic category. A typical episodic memory is what you did last summer, or what you had for lunch yesterday.

According to Tulving (2002, p. 5) "Episodic memory is a recently evolved, late-developing, and early deteriorating past-oriented memory system, more vulnerable than other memory systems to neuronal dysfunction, and probably unique to humans". Tulving emphasized that episodic memory requires the ability to mentally travel in time, to re-experience previous 
experiences in one's own life. At one time, episodic memory is believed to have evolved from semantic memory (Tulving, 2002). According to Tulving (1983), for a memory of an event to be episodic there are three criteria: "what, where and when".

Episodic memory is the system most vulnerable to aging (Bäckman, Small, $\&$ Wahlin, 2001) and diseases such as Alzheimer's disease (Bäckman, Mäntylä, \& Herlitz, 1990). From early to late adulthood, episodic memory performance declines fairly slowly and continuously (Nilsson et al., 1997; Salthouse, 1998).

The direction and size of sex differences in episodic memory tasks vary as a function of type of task. There are several ways in which to categorize episodic memory tasks. For the purpose of the present thesis, the following categories have been used: words or stories, pictures, faces, odors, object location, and wayfinding. These categories are, however, not to be interpreted as different memory systems, but as several different types of memory tasks, used to assess different aspects of episodic memory.

Testing can consist of free recall, cued recall and/or recognition tasks. In a test with free recall, the participant is first presented with a stimulus material and immediately thereafter or later is asked what he or she can remember of the stimulus material. In cued recall there are cues as to what was to be remembered (e.g., one or more letters of the word). In contrast, in a recognition task, the participant is first presented with material (usually a number of pictures or words) and immediately thereafter or after a delay is presented with a number of words or pictures from the original presentation intermixed with distractors, and is asked to determine which ones were in the original presentation.

\section{Words or Stories}

A common test of episodic memory is words or stories. The participant is presented with a number of words, either verbally or visually, and immediately or after a delay is asked to recall (free recall or cued recall) or recognize the presented words. Tests assessing memory of pictures are conducted in a similar way.

Sex differences favoring women in memory for words have been found (e.g., Bolla-Wilson \& Bleecker, 1986; Ruff, Light, \& Quayhagen, 1988) 
and seem to already be present at an early age. Kramer, Delis, Kaplan, O'Donnell, and Prifitera (1997) found that, already in the age group of five to six years, girls perform at a higher level than do boys in free delayed recall of a word list, and similar results were evident in the other age groups tested (i.e., boys and girls up to 15-16 years of age). Temple and Cornish (1993) also found these differences in children nine to eleven years of age. Even among samples with very old and healthy adults (i.e., 76 years or older), women have been found to outperform men in word recall (e.g., Herlitz et al., 1997; Hill et al., 1995).

Similar results are found in memories for stories with women normally performing at a higher level than men (e.g., Zelinski, Gilewski, \& Shaie, 1993), although some sex differences in the opposite direction have been found in special cases, e.g., when the material to be remembered is erotic in nature. One such study (Geer \& McGlone, 1990) found that women performed at a higher level in identifying previously presented romantic sentences, whereas men performed at a higher level in identifying previously shown erotic sentences.

\section{Pictures}

Tests assessing memory for different types of visual stimuli are common in the research literature. Women normally perform at a higher level than do men in recall and recognition of concrete pictures (e.g., Herlitz et al., 1999). However, in recognition tasks of a more abstract nature (e.g., ink blots and snow crystals) the sex differences disappear (e.g., Goldstein \& Chance, 1970). Men and boys, on the other hand, outperform women and girls in memory for cars (e.g., Davies \& Robertson, 1993; McKelvie, Standing, St. Jean, \& Law, 1993). It is possible that this is the result of interest; that is, that people tend to remember things that they are interested in to a greater extent than objects that have lesser meaning to them. In this case it is likely that men have greater knowledge of and interest in cars, and perhaps women in meaningful pictures, whereas ink blots and snow crystals do not appeal to either men or women and therefore show no sex differences. 


\section{Faces}

Memory for faces is an ability that we as humans need to have in order to function properly. It is an interesting type of memory, as we are able to recognize literally thousands of faces, regardless of changes in hairstyles, hair color, makeup, and eyeglasses (Diamond \& Carey, 1986).

In a typical face recognition task, the subject is presented with slide pictures of faces, each for a short amount of time, and many pictures directly following each other. After some delay, the subject is presented with another group of pictures and for each picture is asked to determine whether it has been shown previously or not. Women normally perform at a higher level than do men in face recognition tasks (e.g., McKelvie, 1981).

Several studies have, however, failed to find sex differences in face recognition among school-aged children (e.g., Freire \& Lee, 2001; Temple $\&$ Cornish, 1993). On the other hand, in a study of very old adults (aged 75-96 years old), Wahlin et al. (1993) found a decline in face recognition with age, women generally performing at a higher level than did men. Age differences have been found in face recognition, with young adults performing at a higher level than do old adults (e.g., Bartlett \& Leslie, 1986; Larrabee \& Crook, 1993).

\section{Odors}

In 1993, Lehrner found that women perform at a higher level than do men in episodic odor memory. Higher verbal ability in women is one possible explanation (Hyde \& Linn, 1988). Women's higher verbal ability in regard to olfactory information has been shown to be age-invariant (e.g., Corwin, Loury, \& Gilbert, 1995; Doty et al., 1984).

Öberg, Larsson and Bäckman (2002) found no sex differences in episodic memory for unfamiliar odors. However, women outperformed men in tasks of memory for familiar odors and in odor identification, the two tasks involving verbal processing. Controlling for odor naming, no sex differences were found, which according to the authors suggests that women's higher performance in episodic odor memory is related to women's higher ability to identify odors. 


\section{Object Location}

Whereas women perform at a higher level in most episodic memory tasks tapping verbal abilities, some tasks are designed to be more visuospatial in nature. One of these tasks requires the participants to remember a number of objects and their locations in space. These tasks normally have both verbal and spatial components.

Eals and Silverman (1994) showed participants an illustrated array of tools and the participants were later asked to mark tools that had been added after the initial presentation. In a second task, participants were asked to mark the tools that had exchanged places with other objects since the original presentation. Results showed a nonsignificant trend favoring women in object memory, and women performing at a significantly higher level in location memory. In a similar study, with objects moved to previously unoccupied areas, James and Kimura (1997) found no sex differences in this task and hypothesized that women may process object identity and location together in overlapping brain systems, whereas men may process them separately.

The classic game of Memory consists of a number of cards with pictures of different objects, and each picture appearing identically on two cards. The cards are mixed and placed face down on a table and the object is to turn over as many identical pairs as possible, turning over two cards at a time, in as few turns as possible. Thus, there is a verbal and a spatial component in this game. McBurney, Gaulin, Devineni, and Adams (1997) found that among college students, women outperformed men in this game. Thus, it seems that women have the advantage in tasks assessing object and location memory. It is possible that women have a stronger interest in such tasks and thereby gain the advantage. In these tasks it is also possible to use verbal labels to facilitate remembering, which could help explain the female advantage.

\section{Wayfinding}

Most tasks assessing wayfinding abilities and strategies have been found to favor men. Tasks involving navigation, reading or learning maps, or retracing a memorized way between two points are tasks in which men excel (e.g., Galea \& Kimura, 1993). Men are more accurate than are women in judgments of directional relationships and in pointing to 
landmarks or locations that are out of sight (e.g., Astur, Ortiz, \& Sutherland, 1998; Holding \& Holding 1989; Lawton, 1996; Lawton, Charleston, \& Zieles, 1996; Lawton \& Morrin, 1999). Women, on the contrary, seem to remember landmarks and their locations more accurately than do men (e.g., Eals \& Silverman, 1994; Galea \& Kimura, 1993; Silverman \& Eals, 1992).

An interesting finding is that men, when describing the way to get from one place to another, are more prone to use cardinal directions (i.e., North, East, South and West) and distances whereas women are more likely to use landmarks and objects, such as signs, statues or names (Galea \& Kimura, 1993). Women also seem to perform at a higher level when following directions with landmark information, and men excel when following cardinal directions and distances (Saucier, Green et al., 2002).

\section{Other Cognitive Abilities}

\section{Spatial Abilities}

Spatial abilities deal with "representing, transforming, generating, and recalling symbolic, nonlinguistic information" (Linn \& Petersen, 1985, p. 1482). Researchers have defined several different, and partly overlapping, categories of spatial abilities. In the present thesis, four categories of spatial abilities will be discussed. Linn and Petersen identified three of these concepts, namely spatial perception, mental rotation and spatial visualization. A fourth identified concept is spatiotemporal ability (Halpern, 2000). The magnitude of sex differences in spatial abilities varies with the type of task at hand.

In spatial perception tasks, the subject is asked to find the horizontal or vertical axis in a picture while disregarding other information (Linn \& Petersen, 1985), such as deciding what the water level would look like (i.e., what angle it would have) in a picture of a tilted glass. Men perform at a higher level than do women in tasks assessing this ability (e.g., Robert \& Harel, 1996).

Mental rotation tasks require the subject to identify what a two-dimensional or three-dimensional object would look from a different angle. The most common test assessing this ability is the modified version of the Shephard- 
Metzler Mental Rotation Test for group administration by Vandenberg (1971). Large and consistent sex differences favoring men are found in these tasks (two-dimensional mental rotation task: Collins \& Kimura, 1997; three-dimensional e.g., Masters \& Sanders, 1993; Voyer, Voyer, \& Bryden, 1995) and these differences hold throughout life (Delgado \& Prieto, 1996). Younger adults have not only been shown to perform at a higher level, but also more quickly, than do older adults in these tasks (e.g., Clarkson-Smith \& Halpern, 1983; Hertzog, Vernon, \& Rympa, 1993).

Spatial visualization requires a complex analysis in multiple steps using spatial information. In these types of tasks, the subject is often asked to find embedded figures in a complex pattern, determine how a flat object would look if folded (paper folding), or how an object would look if unfolded. No significant sex differences were found in spatial visualization in two independent meta-analyses (Linn \& Petersen, 1985; Voyer et al., 1995), although Voyer et al. found tendencies favoring men in these tasks.

In tasks assessing spatiotemporal ability, the participant is asked to make judgments about moving pictures or objects, such as when a moving object is in line with a stationary object or when a moving object will reach a certain point (Halpern, 2000). Men perform at a higher level than do women in these tasks (e.g., Law, Pellegrino, \& Hunt, 1993; Watson \& Kimura, 1991).

Thus, a fairly clear picture emerges with respect to performance in various spatial tasks: men outperform women. Moreover, these sex differences in spatial tasks seem to hold in different parts of the world, such as Europe (e.g., Berry, 1966; Herlitz et al., 1999), Asia (e.g., Mann, Sasanuma, Sakuma, \& Masaki, 1990; Silverman, Philips, \& Silverman, 1996), Africa (e.g., Munroe \& Munroe, 1971), and North America (e.g., Law et al., 1993; Mann et al., 1990). Interestingly, two early studies (Berry, 1966; MacArthur, 1967) found that although these sex differences seem to be cross-cultural, Eskimos seem to be an exception: women perform at a higher level in spatial tasks than do men.

Regarding age differences, Voyer et al. (1995) found that sex differences in spatial perception, mental rotation and spatial visualization increased with age when they divided the participants into three age groups: under 13 years of age, 13-18 years, and over 18 years. In contrast, sex differences in 
tasks assessing mental rotation have been found already at four-and-a-half years of age (Levine, Huttenlocher, Taylor, \& Langrock, 1999). Despite a search for information on age differences in spatiotemporal ability, no such studies have been found.

\section{Motor Skills}

One of the largest and most consistent sex differences in cognition is found in tasks requiring motor skills, such as accuracy in aiming (e.g., dartthrowing) or intercepting a flying object (e.g., catching a ball) (Kimura, 1999). Men perform at a higher level than do women in such tasks (e.g., Watson \& Kimura, 1991; Westergaard, Liv, Haynie, \& Suomi, 2000). These differences in throwing accuracy have been found regardless of sporting/throwing experience, strength or physique, or gender identity (Hall \& Kimura, 1995). These sex differences seem to emerge early in life as they have been found in children as young as three to five years of age (Lunn, 1987 as cited in Kimura, 1999).

In the Purdue Pegboard task, participants are asked to move small pegs and put them in holes in a wooden board (e.g., Desrosiers, Herbert, Bravo, \& Dutil, 1995). The task is often performed with only the right hand, only the left hand, and with both hands simultaneously. Women have been found to outperform men in this task (e.g., Nicholson \& Kimura, 1996). One research group (Peters, Servos, \& Day, 1990) believed that the female advantage is due to women having smaller hands, but others have not drawn the same conclusions (Hall \& Kimura, 1995; Nicholson \& Kimura, 1996). Another study found that women have a higher degree of control over distal muscles than do men (Kimura \& Vanderwulf, 1970). Girls have also been found to outperform boys at imitating hand postures already in the age group three to five years (Ingram, 1975). In sum, although men seem to outperform women in many tasks assessing motor skills, the Purdue Pegboard task is an exception.

\section{Attention}

Attention refers to the process of selecting stimuli for further processing from all of the information available. It can be studied in numerous different ways, for example with the Brief Test of Attention (BTA; Spreen \& Strauss, 1998), in which strings of letter/number combinations intermixed and of varying lengths are played from an audiocassette for the participant. The participant's task is to remember how many letters (or 
numbers) were read each time. It can also be tested as a task of divided attention. In such tasks, the participant does two things at once, for instance, using the above example, while listening to the string of letter/word combinations, the participant is required to sort a deck of cards into two piles: one with red cards and one with black.

Another task often used to assess attention is the Stroop task, which was used in Study III. The Stroop task consists of three parts: First, participants are shown and asked to read aloud as quickly and accurately as possible the names of colors (green, blue, red, and yellow) printed in black ink. In the second part, participants are asked to name the color of various colored boxes. Finally, participants are presented with names of colors printed in incongruently colored ink, for example the word "red" printed in blue. The participants are asked to name the color of the ink as quickly and accurately as possible. The time it takes the participant to complete the task and the number of errors made serve as the dependent variable.

Most studies have found no sex differences in the Stroop task (Daniel, Pelotte, \& Lewis, 2000). The few studies that have found sex differences have been in the color-naming and word-reading parts, and have favored women (Strickland, D'Elia, James, \& Stein, 1997). However, there are no apparent sex differences in the color-interference part (Boone \& Lu, 2000). Brink and McDowd (1999) found a significant age-related decline in the color-interference part, whereas older and younger participants performed comparably on the colored boxes.

In related tasks, women have been found to outperform men in naming colors and shapes as quickly and accurately as possible (e.g., Saucier, Elias, $\&$ Nylen, 2002). Saucier, Elias et al. suggested that the difference was due to women's advantage in speeded naming tasks and access to verbal labels, or women's higher ability to produce and execute the necessary motor sequences to articulate the names.

\section{Summary}

Sex differences have been found in some cognitive abilities, but not in all. The magnitude and direction varies with the type of task; women excel in some tasks, and men have the advantage in others. 
The largest and most consistent sex differences that have been found in memory are those dealing with episodic memory. Women have been found to outperform men on tasks that tap verbal abilities such as words and stories, concrete picture recall and recognition (e.g., Herlitz et al., 1999), on odor recognition (e.g., Lehrner, 1993) as well as on face recognition tasks (e.g., McKelvie, 1981). Men, on the other hand, perform at a higher level than do women on episodic memory tasks tapping visuospatial abilities, such as wayfinding (e.g., Galea \& Kimura, 1993).

On the tasks primarily assessing cognitive abilities other than memory, a large sex difference favoring men has been found in tasks assessing visuospatial abilities, such as mental rotations and spatiotemporal abilities (e.g., Law et al., 1993; Watson \& Kimura, 1991). In addition, men have the advantage in aiming and/or catching tasks (e.g., Watson \& Kimura, 1991; Westergaard et al., 2000). Women, in contrast, perform at a higher level on the Purdue Pegboard assessing fine motor skills (e.g., Nicholson \& Kimura, 1996).

Few, if any, of the tasks described here can be conducted without the use of memory. For instance, to perform the Purdue Pegboard task, the participant must use procedural memory in order to move the pegs into their positions. However, the tasks have been categorized to follow their primary classification and no attempt has been made to classify them in terms of the memory systems on which they rely.

\section{Cognition and the Brain}

The following section is an orientation in the interplay between the brain and cognitive tasks.

Needless to say, the brain is a very complex structure, and was until fairly recently only possible to study post-mortem. With the help of new techniques such as functional magnetic resonance imaging (fMRI) and positron emission tomography (PET), a great deal of research has been conducted regarding the brain and cognitive functions. There are high expectations that these techniques will help answer many questions in memory research. 
Very generally, both PET and fMRI techniques build on the principle that brain areas activated while performing a task experience an increased blood flow (PET) or increased level of blood oxygenation (fMRI), which shows on the images taken (Raichle, 1994). Functional brain imaging techniques have provided evidence that changes in activity in numerous brain areas result from even very simple tasks (e.g., Deiber et al., 1997). In addition to women having smaller brain volume, even when correcting for body size (e.g., Ankney, 1992; Dekaban, 1978), they have also been found to have a faster blood flow rate in relation to brain weight than do men when performing the same cognitive tasks (e.g., R.C. Gur et al., 1982; R. E. Gur \& Gur, 1990). It is possible that the increased blood flow compensates for women's smaller brains (Gur \& Gur, 1990). In addition, men have been found to have more neocortical neurons than do women, although the relative decrease with age is similar for men and women (Pakkenberg \& Gundersen, 1997).

The corpus callosum binds together the left and right hemispheres of the brain. Some studies have found that women have a larger corpus callosum than do men (e.g., Steinmetz, Staiger, Schlaug, Huang, \& Jancke, 1995), although this line of thought has been challenged. One review claimed that there are no sex differences in the size or shape of the corpus callosum (Bishop \& Wahlsten, 1997). However, if it is true that women have larger corpus callosa, this would support the theory that they have more bilateral activation in cognitive tasks, whereas men have more lateralized activation. This would mean that women, to a higher extent than men, use both hemispheres whereas men more often use only one hemisphere of the brain in solving cognitive tasks.

Two areas of the brain that have been found to be of specific interest to memory researchers are the hippocampus and the frontal lobes (e.g., Nyberg \& Cabeza, 2000). The hippocampus curves into both hemispheres of the brain, and in male and female rats has been found to differ and has been claimed to explain the different strategies used among rats in solving spatial navigation tasks (McEwen, Alves, Bulloch, \& Weiland, 1997). In humans, studies on brain surgery patients have shown that when the right hippocampus is removed, a decline in visual memory is found in women but not in men (Trenerry, Jack, Cascino, Sharbrough, \& Ivnik, 1996). Thus, there is some support for the hypothesis that men's and women's brains work differently. 
In a large-scale review of fMRI and PET studies, Cabeza and Nyberg (2000) found that the prefrontal cortex (an area in the front of the brain) is very often involved in working memory. In semantic memory retrieval, there seems to be prefrontal activity in the left hemisphere, though not in the right, and in episodic memory retrieval there is often a right-sided lateralization in prefrontal activity. However, in episodic memory encoding, the brain regions activated were prefrontal, cerebellar (i.e., the hindbrain), and medial temporal (i.e., at the side of the brain). When encoding verbal materials there was a strong left-hemispheric lateralization, whereas the retrieval of these materials results in activity that is lateralized to the right. Thus, the frontal lobes, in addition to other parts of the brain, seem to be important in memory functioning.

The activation patterns in retrieval of episodic memories seem to be very similar in men and women; however, Nyberg, Habib, and Herlitz (2000) found that even with similar performance levels, the patterns differed slightly. Women showed a larger increase in activation in two regions of the anterior cingulum (i.e., in the middle of the brain) and in a frontal region, whereas men showed a decrease in this frontal region compared to baseline levels.

\section{Cognition and Aging}

In a recent study, Small, Tsai, DeLaPaz, Mayeux, and Stern (2002) investigated whether memory decline is a part of normal aging, or a disease. Small et al. showed that the hippocampal function declines with age and that this is related to memory deterioration. The researchers thus concluded that some memory decline with age is normal. Also, Herlitz et al. (1997) found a similar decline with age among men and women in memory performance.

For the purpose of the present thesis, only atrophy and white matter changes will be discussed. These are two of the most common age-related changes. Atrophy involves shrinkage of the brain with increasing fluids as a result, and is caused by disease, old age or injury. Atrophy is usually measured in cortical (the outer layer of the brain) and subcortical areas (under the cortical areas) of the brain. Age-related brain atrophy varies with 
regard to location and degree in both men and women, although most studies have found that men have a higher degree of age-related brain atrophy (e.g., Xu et al., 2000).

In the brain and spinal cord there are large axon tracts, which are white in color, and therefore named white matter. In both normal and pathological aging, white matter changes occur in the brain. White matter changes can be found in two areas of the brain - subcortically, and periventricularly, i.e., in the area nearest to the ventricals, in the middle of the brain. In a longitudinal, large-scale study, de Groot et al. (2002) found that participants with severe periventricular white-matter changes had a decline in cognition (measured with the Mini-Mental State Examination) almost three times faster than the average, whereas no relationship was found between subcortical white matter changes and cognitive decline. White matter changes seem to occur to a larger extent in men than in women (e.g., Passe et al., 1997).

\section{Research Objectives}

\section{The Purpose of the Present Studies}

The overall aim of this work is to study sex differences in memory and other cognitive functions. The three studies investigate different aspects of sex differences in cognition and discuss possible explanations.

The purpose of the first study was to examine if the sex differences found favoring women in episodic memory tasks have to do with the verbal nature of most episodic memory tasks, as women also outperform men in most verbal tasks.

In the second study, the issue of possible verbal components facilitating memory tasks for women was again addressed. This time the study used face-recognition tasks, in which women normally outperform men. Two things were investigated in this study. First, is women's advantage in face recognition due to a greater ability to recognize faces per se, or does the female advantage lie in the ability to recognize women's faces? And 
secondly, do women use, and benefit from using, verbal labels in order to recognize faces to a greater extent than do men?

In Study III the aim was to examine the relationship between sex differences in cognition and age-related changes in the brain in a sample of healthy, older adults and to determine if sex differences in cognitive abilities could be attributed to sex differences in the aging brain. Atrophy and white matter changes as well as a variety of cognitive tasks were assessed.

\section{Study I}

While it is an established fact that women outperform men in most episodic memory tasks and that women often perform at a higher level than do men in tasks containing a verbal component, this study aimed at determining whether women use their higher verbal ability in episodic memory tasks in which it is possible to use verbal labels. Additionally, the aim was to see if episodic memory tasks with a highly limited verbal component and a larger visuospatial component would still see women outperforming men.

Ninety-one men and 94 women, 20-40 years of age, with no significant differences between the sexes with regard to age, years of education, and self-rated state of health participated in the study. The participants were tested on a large number of tasks relating to verbal, visuospatial and episodic memory skills. The tasks varied in how heavily they relied on verbal encoding (from very little to very much).

Whereas there were no differences between men and women in the verbal tasks of phonological fluency (generating as many words as possible beginning with a given letter in a limited time) and synonyms (generating as many synonyms for a given word in a limited time), the results on the visuospatial tasks were as predicted, with men outperforming women on the tasks of paper-folding, mental rotation and water-level.

The results on the episodic memory tasks were mixed. On a facerecognition task women performed at a higher level than did men, although men outperformed women on a task named Cubes. In the Cubes task, the participants were shown a slide picture for ten seconds depicting a number of cubes stacked on top of each other, with approximately half the sides being black and the other white. Following a short delay, the participants 
were asked to mark, on an answer sheet displaying the same cubes, which sides had been black. There were six such tasks of increasing difficulty. Overall, men performed at a higher level than did women. When analyzing the six tasks separately, it was found that on the first and easiest task, women performed on a significantly higher level than did men. As the level of difficulty increased, and the possibility to use verbal labels decreased, men gradually gained a larger and larger advantage relative to women. Six other episodic memory tasks, varyingly visuospatial in nature, were assessed. None of these showed significant sex differences.

The results of this study showed that despite the expected results of women outperforming men in the verbal tasks not being present, men outperformed women in the visuospatial tasks and women expectedly outperformed men in the face-recognition task. The results also showed that the less verbal and more visuospatial a task was, the stronger the male advantage, whereas women tended to perform at a higher level on verbal episodic memory tasks, although the differences were sometimes small.

\section{Study II}

Study I showed that women outperform men in most episodic memory tasks in which the material can be labeled verbally. Women have also repeatedly been found to perform at a higher level than do men on facerecognition tasks. Thus, Study II investigated two things: whether women do not outperform men in face recognition per se, but rather in the recognition of faces of females or, alternatively, whether women use verbal labels when encoding and recognizing faces and therefore have the advantage.

So, why would women be especially proficient in the recognition of female faces? One possible explanation is that women, to a greater extent than men, are exposed to pictures of women in women's magazines and advertising and that women have a tendency to compare themselves and study other women's looks on a daily basis.

The 192 participants in this study were 20-40 years of age. Two groups of participants were established, with approximately equal numbers of men and women in each group. Each participant was asked to perform two facerecognition tasks, in one case each picture being shown for a very short time (one second), and in one case each picture being shown for three 
seconds. The test battery also included verbal and visuospatial tasks. Approximately half of the participants were shown normal full-face color photographs in both face recognition tasks, whereas the other participants were shown color face photographs in which the hair, ears, throat and clothing had been removed using a computer program. All that remained were egg-shaped faces depicting only the facial features, henceforth referred to as "features only". The other tasks were identical for both groups.

If the hypothesis of women performing on a higher level in the recognition of female faces, then this should be the case in all four (time/type of picture) presentation conditions relative to men's performance in these conditions. However, if women use verbal labels while encoding and recognizing pictures then they would be expected to outperform men primarily in the full-face, long presentation condition, and least in the fast presentation of the "features only" faces.

As expected, results showed that women outperformed men in face recognition. Closer analysis indicated that the differences emerged from women outperforming men in the recognition of faces of women regardless of type of stimuli or presentation time, whereas no sex differences were found in the recognition of faces of men.

The results indicated that women in general do not outperform men in face recognition per se, but rather in the recognition of female faces. The reasons for this could be that women, to a greater extent than men, compare themselves to other women as well as are constantly exposed to pictures of women in advertising, women's magazines, etc. Women may be more interested in how they look, and in how they would like to look than men and therefore compare themselves to each other to a greater extent than do men.

\section{Study III}

It has been established that most cognitive abilities in men and women decline with increasing age. The human brain also undergoes changes with advancing age, and these changes could affect cognitive performance. If the brains of men and women are different, as research suggests, it is reasonable to believe that men's and women's brains age differently as 
well. In this study, the object was to examine whether the sex differences in cognitive abilities were related to sex differences in the aging brain.

One hundred and twenty-nine participants, 65 men and 64 women, 64-74 years of age, were included in the study. There were no differences between the two groups with regard to age, years of education, or scores on a test of global functioning (MMSE).

The participants were tested on a number of tasks assessing different cognitive abilities: attention, motor skills, working memory, semantic memory and episodic memory. Two different kinds of age-related changes were measured for each participant using Magnetic Resonance Imaging (MRI), namely atrophy and white matter changes (WMCs).

Results showed that there were sex differences favoring women in the Purdue Pegboard task, measuring fine motor skills, and in Letter Digit Substitution, measuring working memory, but no other cognitive task showed significant sex differences. The brain analyses revealed that men had a higher degree of subcortical atrophy than did women. No other sex differences in brain measures were found.

When the effects of Letter Digit Substitution and Purdue Pegboard were tested with subcortical atrophy kept constant, results showed that subcortical atrophy, to some extent, could explain the sex differences in Purdue Pegboard with both hands, but not the other cognitive tasks.

The results of the cognitive tasks are in line with previous studies, whereas the picture of sex differences in brain aging is more mixed. Of the tasks assessing different cognitive abilities, only the sex differences in the test of motor skills (Purdue Pegboard, performed with both hands) could to some extent be explained by subcortical atrophy. Therefore, the sex differences in Letter Digit Substitution and Purdue Pegboard performed with the left and right hands, respectively, must have some other explanation than atrophy or white matter changes.

\section{Summary}

In sum, the following conclusions can be drawn from the three studies: The female advantage in episodic memory tasks seems to be related to women's higher verbal ability, whereas it seems that men have an advantage in 
visuospatial episodic memory tasks (Study I). In face recognition, women's higher performance level seems to be related not to their higher verbal ability or face recognition per se, but to their higher performance in the recognition of other women (Study II). Sex differences in a task of motor skills (Purdue Pegboard using both hands) could to some extent be explained by sex differences in the aging brain (subcortical atrophy), although we did not find support for sex differences in other tasks of motor skills (Purdue Pegboard using the right and left hands, respectively) or in Letter Digit Substitution being explained by sex differences in atrophy or white matter changes (Study III).

\section{Discussion}

It has been known for some time that women excel in episodic memory tasks tapping verbal abilities. However, as Study I showed, this seems to be related to their higher verbal ability rather than episodic memory per se. Men, on the other hand, have the advantage in episodic memory tasks that are visuospatial in nature.

Face recognition, a most important ability in people's everyday lives, is a task in which women constantly outperform men. This difference seems to be related to women's higher ability to recognize other women's faces rather than faces in general, according to the results in Study II. No support was found for the hypothesis that women use verbal labels when encoding and recognizing faces and thus, face recognition seems to be a non-verbal task. Some studies have, however, found an own-sex bias in these types of tasks, meaning that women tend to recognize the faces of other women and men recognize other men's faces to a larger extent than they recognize members of the opposite sex (e.g., Vokey \& Read, 1988). Studies have also shown that participants are more accurate in recognizing pictures of people belonging to their own ethnic group than of those belonging to other ethnic groups (e.g., Meissner \& Brigham, 2001).

Many cognitive abilities have been found to decline with age among both men and women. In Study III, the expected sex differences in cognitive tasks were found, and although the picture with regard to sex differences in atrophy and white matter changes is mixed, the results were in line with the 
main stream of this research. However, there was little support for these sex differences being explained by atrophy or white matter changes in older adults and thus, there must be some other explanation.

So, then, why do these sex differences in cognition exist? Several possible explanations have been proposed, ranging from evolutionary to biological differences in the brain to psychological and social explanations.

\section{Evolutionary Explanations}

Some evolutionary theories regarding sex differences in cognition have been put forward. According to these theories, men very early developed skills in aiming and calculating the proper time to shoot in order to hit a moving animal. Women, on the other hand, developed fine motor skills and memory for locations in the vicinity of the home regarding where berries, fruits and other foods could be found (Eals \& Silverman, 1994; Silverman $\&$ Eals, 1992). De Courten-Myers (1999) hypothesized that women may have developed an increased awareness of context as a result of caring for children and home and that men developed an ability to consider facts in isolation to each other.

In line with these evolutionary explanations, studies have found that men outperform women in aiming (Watson \& Kimura, 1991), and predicting when an object would reach a certain point (e.g., Wright, Smith, Geffen, Geffen, \& Martin, 2000) whereas women outperform men in recall of spatial arrays (e.g., Silverman \& Eals, 1992) as well as in remembering spatial relationships between objects (e.g., Eals \& Silverman, 1994; Silverman \& Eals, 1992). However, the evolutionary view does not explain women's higher verbal ability, although it could be argued that whereas the men were away and hunting for most of the day and had to be quiet in order to not scare the prey, the women stayed together and took care of the young, talked more and, perhaps, used verbal labels to remember where fruits and berries could be found. This could be one explanation for women's higher verbal abilities. It is also possible that women developed fine motors skills through picking berries and making baskets, which could explain women's advantage in tasks such as Purdue Pegboard.

\section{Interest Hypothesis}

McKelvie et al. (1993) claimed that cognitive sex differences depend on differential interests of men and women, and that these determine what 
individuals remember. They compared sex differences in face recognition, in which women outperformed men, and recognition of cars, in which men outperformed women. Results were thus interpreted as being due to men's and women's differential interests. Similarly, in semantic fluency tasks, women have been found to outperform men in generating names of fruits, whereas the opposite is true of generating names of tools (Capitani et al., 1999). It is also possible that interest could be one explanation to women's higher performance in face recognition. Perhaps women, consciously or not, compare themselves to other women and thereby perform at a higher level than do men in recognition of other women. Contrary to Study II, some studies have shown that men outperform women in the recognition of other men (e.g., Vokey \& Read, 1988). Such results could be interpreted as men comparing themselves to other men, just as women seem to compare themselves to pictures of other women.

\section{Biological Explanations}

Many researchers believe that a large part of the explanation of why cognitive sex differences exist has to do with biology. Roughly, biological explanations can be divided into three partially overlapping categories: the effect of sex hormones on the brain both before and after birth, genetic differences regarding sex and sexual orientation, and anatomical differences between the male and female brains.

\section{Hormonal Effects}

Already in the early stages of pregnancy, the fetus is exposed to large amounts of sex hormones and the levels of testosterone are 10 times greater in males than in females (Swaab, Zhou, Fodor, \& Hofman, 1997). Sex hormones affect brain development from early in fetal development to very old age (Collaer \& Hines, 1995; Hines \& Collaer, 1993). According to one theory, the left hemisphere is at greater risk in prenatal development than is the right, because the developmental process takes a longer time for the left hemisphere (Geschwind \& Galaburda, 1987). High levels of testosterone in the prenatal phase are believed to slow the neuronal growth in the left hemisphere, resulting in right-hemisphere dominance (often resulting in left-handedness), according to this theory. Studies have shown that more men than women are left-handed (e.g., Halpern, Haviland, \& Killian, 1998), which could be a result of male fetuses being exposed to higher levels of prenatal testosterone. 
According to an alternative hypothesis (Levy 1976; Levy \& Nagylaki, 1972), spatial tasks are performed optimally when the ability is lateralized in the brain. However, if the lateralization is weak or if two or more cognitive abilities are lateralized to the same part of the brain, they do not have the "space" to develop completely and abilities consequently suffer. Levy (1976) explained sex differences in verbal and spatial abilities by claiming that women more often than men have a bilateral representation of verbal abilities, and that visuospatial abilities therefore do not have enough "space". Men, on the other hand, have verbal and visuospatial abilities lateralized to different hemispheres. The female advantage in verbal abilities is explained by language functions involving larger areas in the brain, thus the bilateral representation is at an advantage as it is able to draw from these different areas.

Studies have provided some evidence for differences in functional asymmetry. For example, Wood, Flowers, and Naylor (1991) found sex differences in cerebral blood flow while performing verbal tasks, and Shaywitz et al. (1995) found similar differences when measuring with fMRI. In addition, it has been found that women do not suffer from impaired language as a result of local trauma to the head to the same extent as do men (McGlone, 1980). It is believed that this is because women, to a greater extent than men, are able to compensate using the uninjured hemisphere.

\section{Sexual Orientation and Cognition}

Theories regarding connections between sexual orientation and cognitive performance concern beliefs that homosexual men are more cognitively similar to women than to heterosexual men, and that sexual orientation is genetic (e.g., Kimura, 1996). This line of research has rendered a great deal of interest in recent years. Interestingly, not much research has been conducted on cognitive abilities in homosexual women; therefore, any conclusions about such women would be premature (Halpern, 2000).

In aiming tasks, homosexual men have been found to perform on a level somewhere between heterosexual men and women (Hall \& Kimura, 1995; Sanders \& Wright, 1997). Hall and Kimura and Gladue, Beatty, Larson, and Staton, (1990) also found that homosexual men did not perform as well 
as did heterosexual men on mental rotations and other visuospatial tasks. In addition, McCormick and Witelson (1991) found that homosexual men scored on a level between the levels of heterosexual men and women, with no significant differences from the group of women on three spatial tasks and one verbal fluency task. Thus, there is some evidence pointing toward sexual orientation, at least in part, being a genetic trait.

\section{Anatomical Sex Differences and Cognition}

In general, men's brains are slightly larger and heavier than are women's and this difference is present very early in life (e.g., Ankney, 1992; Dekaban, 1978). Studies on anatomical and functional differences in the brain have focused mainly on the differences in lateralization during different types of tasks. There is some support for the male brain being more asymmetrical than the female brain regarding cognitive functions (Hiscock, Perachio, \& Inch, 2001). In women, speech seems to be less dependent on the left hemisphere, and spatial and visuoperceptual functions less dependent on the right hemisphere, than in men (Halpern, 2000). There is conflicting evidence of sex differences in the size of the larger corpus callosum, binding the hemispheres together, (e.g., Bishop \& Wahlsten, 1997; Davatzikos \& Resnick, 1998). Cognitive sex differences have been related to differences in the size and shape of the corpus callosum (Collaer \& Hines, 1995 (for a review); Hines, Chiu, McAdams, Bentler, \& Lipcamon, 1992). However, the functional significance of anatomical differences in the brain is largely unknown (e.g., Fitch \& Bimonte, 2002).

\section{Social Explanations}

Social explanations concern the surrounding environment and the effects of toys, parental upbringing, neighborhood, social stimulation, peers and schooling in addition to cultural background, socioeconomic status, etc. (Maccoby \& Jacklin, 1974). These factors affect our lives and the skills we develop. It is likely that a person pursues a hobby such as darts if he or she is good at it, and pursuing the hobby includes practicing and thereby improving skills even more.

\section{The Psychobiosocial Model}

In several papers, Halpern (e.g., Halpern, 2000; Halpern \& Ikier, 2002; Halpern \& Tan, 2001) has contrasted the classical nature versus nature dichotomy with what she calls a psychobiosocial model. According to this 
model, "biology and environment are as inseparable as conjoined twins who share a common heart" (Halpern \& Tan, 2001, p. 395). There are many factors that together determine the performance levels of an individual; for example genetic and biological factors, learning, thoughts, behaviors, experiences and the environment (Halpern, 2000). This model further claims that some variables can be both biological and social, and cannot readily be categorized as either one or the other. As an example, learning depends on biological variables such as neuronal processes in the brain and psychological factors such as interest, which in turn is also affected by prior learning (Halpern, 1997). Biological, social and psychological influences affect all types of behaviors (Halpern, 2000).

My personal belief is that the reasons for the sex differences described in this thesis include many of the explanations above. The foundations for sex differences in cognition emerge in the fetal phase, when high levels of hormones affect the developing brain. Later, social factors such as toys given and interaction with other children and adults play a large part in the developing child's life. The child will be more curious and interested in certain toys and other objects, resulting in more time spent developing appropriate skills. Thus, in my mind, Halpern's psychobiosocial model seems the most appropriate as it incorporates these different theories.

\section{Changes in Cognitive Sex Differences Over Time}

There has been an overwhelming amount of research conducted on sex differences in cognition. As a result, not all studies point in the same direction. What is important is the pattern of significant results, rather than the mere fact that there are studies that have come to the conclusion that there are no sex differences, or point in the opposite direction, as noted by Sanders, Sjodin, and de Chastelaine (2002).

Some researchers believe that the magnitude of sex differences is declining over time (Hyde \& McKinley, 1997; Feingold, 1988). For instance, Hyde and Linn (1988) found that in verbal abilities, the effect size (the size of the sex difference) had declined by over $50 \%$ for the studies published after 1973 compared with earlier studies (from an effect size of 0.23 to 0.10 , favoring women). Interestingly, a similar pattern with declining sex differences has been found in mathematics performance, in which men 
perform at a higher level than do women (Hyde, Fennema, \& Lamon, 1990). There are several possible explanations for these changes in results over time, according to Hyde and McKinley (1997). First of all, the possibility that these changes are real, and that the sex differences have declined, must be considered. For instance, parents could be more equal than previously in the way they treat their children and the toys that they give. However, it is also possible that more nonsignificant results (i.e., not showing any sex differences) are published now compared with thirty years ago, or that the tests assessed today have a smaller sex bias. If there is a real decline in sex differences, however, has there been a change in performance patterns in men or in women, or in both men and women?

According to Halpern (2000), the decline that Hyde and Linn (1988) found in verbal abilities was due exclusively to more nonsignificant results having been published recently, and if these were excluded the effect sizes would not differ between the time periods. Halpern (2000) also concluded that more scientific journals are now publishing nonsignificant results as opposed to earlier; thus, the increase in publishing data that was previously impossible or almost impossible to publish explains these reports of changes in cognitive sex differences over time.

\section{Caution in Interpreting Results}

\section{Other Important Variables}

Education has been found to be an important variable that can, to some degree, explain differences in cognitive abilities. Kempler et al. (1998) found an effect of education on a semantic fluency task (naming animals) in an ethnically diverse sample. In addition, they found sex differences in the opposite direction than expected, with men performing on a higher level than did women. In a study of spatial abilities, Contreras, Colom, Shih, Álava, and Santacreu (2001) found that men performed at a higher level than did women, regardless of education. Portin, Saarijärvi, Joukamaa, and Salokangas (1995) found a significant effect of education in a number of working and episodic memory tasks in an older sample. Although not all studies find effects of education (e.g., Hassing, Wahlin, \& Bäckman, 1998), it is a variable that should be accounted for in studies on cognitive abilities. 
In every study, results are affected by many different factors. Stress and/or time limits are important factors that are not always accounted for. These factors are important and influence performance. One study found no sex differences in mental rotations, a task normally associated with quite large sex differences favoring men, when there was no time limit (Resnick, 1993), whereas Goldstein, Haldane, and Mitchell (1990) found that the time limits in mental rotations substantially contributed to men's advantage. In similar tasks, Delgado and Prieto (1996) found that it was detrimental to both men and women to receive instructions to work quickly. Thus, there are mixed results as to the effects of time limits.

\section{Strategy}

It has been shown that in some tasks men and women seem to adopt different strategies for solving tasks; this could affect the sex differences found. For example, Lawton and Kallai (2002) found that, in wayfinding tasks, men prefer a global orienting strategy and women prefer strategy based on route information. In other tasks, it is often difficult to study the strategies used and it is perhaps therefore that there seems to be very little research conducted on this topic. It is possible that the strategy used affects the results; this may explain why education is an important variable.

To my knowledge, studies on sex differences in memory using the levelsof-processing framework have not been conducted. It would be interesting to study this with different types of tasks, where the degree to which the material can be labeled verbally is varied. In such a study, participants could be asked to look at different types of pictures and encode them in a shallow or deep fashion. If no sex differences are found then it is likely that the sex differences found in other studies in recognition of pictures are due in part to men and women using different strategies.

\section{The Participants}

It is important to point out that the sex differences in memory are shown in large groups. Whereas there are more men at both the lower and higher ends of the distribution curves, women seem to be a more homogenous group. The variations within the groups are often larger than the variations between the sexes. However, as Kimura (1999) pointed out, if the criterion of no overlap between the two groups were used, then there would be very little acceptable data in behavioral science. This limits the conclusions one can draw from these studies. The differences are not large enough to 
warrant that boys and girls should be educated differently or have separate classes. However, it is possible for both men and women to practice and thereby improve cognitive skills such as spatial abilities (Baenninger \& Newcombe, 1989).

\section{Studies on Sex Differences in Cognition}

A few words of caution must be said of the studies included in the present thesis, as well as for studies in general. The external validity, i.e., referring to the ability to generalize the results to a larger population, is limited when using nonrandom samples. In Study I participants were recruited through advertisements in a free, local newspaper and in Study II participants were recruited on a university campus. Those who chose to participate in the tests are not a representative sample of the population in general. Therefore, the results should not be generalized to people in general without reflection. The participants in Study III, however, were randomly selected for a longitudinal large-scale study (named Betula). A subset of these participants was then randomly selected to be included in a further study (named Cascade), of which Study III is a part.

In addition, a word of caution about tests conducted in a laboratory environment is necessary. The results may not reflect the "true" skills of the participant. How a participant, for instance, performs in a test of face recognition may not match his or her real ability regarding the recognition of faces. In "real life", a person is rarely confronted with only facial pictures of unknown people and is even more rarely tested on his or her ability to recognize the pictures later. However, it is unfortunately difficult to assess memory experiments in anything but an artificial environment.

Although sex differences have been found in several cognitive abilities in a number of studies, it is important to note that in most cases these differences are very limited and thus the conclusions drawn should not be exaggerated. However, what is interesting is that these differences, albeit small, are present. One of the challenges in studying sex differences in cognition is finding these small differences in performance. This often requires large sample sizes and specific tests. 


\section{Concluding Remarks}

Many questions remain to be answered about sex differences in memory and other cognitive abilities. There is a large amount of research currently being conducted regarding these issues. The advancement of science, as well as technological tools such as fMRI and PET, are making it possible to study not only the consequences of sex differences, but also differences in the brain and brain activation patterns.

In the future, it would be interesting if it were possible to test the different proposed explanations against each other and determine truly why these differences exist, as well as discover whether there are changes in sex differences over time as the world becomes more equal with respect to men's and women's societal roles. Often today, psychologists do their research and biologists do theirs; Research crossing the boundaries between different areas of science would be extremely valuable. I am sure that, by working together, we will eventually be able to learn more about sex differences in memory and other cognitive abilities. 


\section{References}

Acevado, A., Loewenstein, D. A., Barker, W. W., Harwood, D. G., Luis, C., Bravo, M. et al., (2000). Category fluency test: Normative data for English- and Spanish-speaking elderly. Journal of the International Neuropsychological Society, 6, 760-769.

Ankney, C. D. (1992). Sex differences in relative brain size: The mismeasure of woman, too? Intelligence. Special Issue: Biology and Intelligence, 16(3-4), 329-336.

Astur, R. S., Ortiz, M. L., \& Sutherland, R. J. (1998). A characterization of performance by men and women in a virtual Morris water task: A large and reliable sex difference. Behavioral Brain Research, 93, 185-190.

Atkinson, R. C., \& Shiffrin, R. M. (1968). Human memory: A proposed system and its control processes. In K. W. Spence \& J. T. Spence (Eds.), The psychology of learning and motivation (pp. 89-195). New York: Academic Press.

Atkinson, R. C., \& Shiffrin, R. M. (1971). The control of short-term memory. Scientific American, 225, 82-90.

Bäckman, L., Mäntylä, T., \& Herlitz, A. (1990). The optimization of episodic remembering in old age. In P. B. Baltes \& M. M. Baltes (Eds.), Successful aging: Perspectives from the behavioral sciences (pp. 118-163). New York: Cambridge University Press.

Bäckman, L., \& Nilsson, L.-G. (1996). Semantic memory functioning across the adult life span. European Psychologist, 1(1), 27-33.

Bäckman, L., Small, B. J., \& Wahlin, A. (2001). Aging and memory. Cognitive and biological perspectives. In J. E. Birren \& K. W. Schaie (Eds.), Handbook of the psychology of aging (5th ed.). San Diego, CA: Academic Press.

Baddeley, A. (1986). Working memory (Vol. 11). New York: Clarendon Press/Oxford University Press.

Baddeley, A. D., \& Hitch, G. (1974). Working memory. In G. H. Bower (Ed.), The psychology of learning and motivation: Advances in research and theory (Vol. 8, pp. 47-89). New York: Academic Press.

Baenninger, M., \& Newcombe, N. (1989). The role of experience in spatial test performance: A meta-analysis. Sex Roles, 20(5-6), 327-344.

Bartlett, J. C., \& Leslie, J. E. (1986). Aging and memory for faces versus single views of faces. Memory and Cognition, 14(5), 371-381. 
Baumeister, R. F. (1988). Should we stop studying sex differences altogether? American Psychologist, 43, 1092-1095.

Berry, J. W. (1966). Tenme and Eskimo perceptual skills. International Journal of Psychology, 1, 202-229.

Bishop, K. M., \& Wahlsten, D. (1997). Sex differences in the human corpus callosum: Myth or reality? Neuroscience and Biobehavioral Reviews, 21(5), 581-601.

Blaxton, T. A. (1995). A process-based view of memory. Journal of the International Neuropsychological Society, 1(1), 112-114.

Bolla, K. I., Gray, S., Resnick, S. M., Galante, R., \& Kawas, C. (1998). Category and letter fluency in highly educated older adults. Clinical Neuropsychologist, 12(3), 330-338.

Bolla-Wilson, K., \& Bleeker, M. L. (1986). Influence of verbal intelligence, sex, age and education on the Rey auditory verbal learning test. Developmental Neuropsychology, 2(3), 203-211.

Boone, K. B., \& Lu, P. (2000). Gender effects in neuropsychological assessment. In Fletcher-Janzen \& Strickland \& Reynolds (Eds.), Handbook of cross-cultural neuropsychology (pp. 73-85). New York: Kluwer Academic/Plenum Publishers.

Brink, J. M., \& McDowd, J. M. (1999). Aging and selective attention: An issue of complexity or multiple mechanisms? Journals of Gerontology: Series B: Psychological Sciences and Social Sciences, 54B(1), 30-33.

Broadbent, D. E. (1958). Perception and communication. London: Pergamon Press.

Capitani, E., Laiacona, M., \& Barbarotto, R. (1999). Gender affects word retrieval of certain categories in semantic fluency tasks. Cortex, 35, 273-278.

Clarkson-Smith, L., \& Halpern, D. F. (1983). Can age-related deficits in spatial memory be attenuated through the use of verbal coding? Experimental Aging Research, 9(3), 179-184.

Collaer, M. L., \& Hines, M. (1995). Human behavioral sex differences: A role for gonadal hormones during early development? Psychological Bulletin, 118(1), 55-107.

Collins, D. W., \& Kimura, D. (1997). A large sex difference on a twodimensional mental rotation. Behavioral Neuroscience, 111(4), 845849.

Contreras, M. J., Colom, R., Shih, P. C., Álava, M. J., \& Santacreu, J. (2001). Dynamic spatial performance: Sex and educational 
differences. Personality and Individual Differences, 20, 117-126.

Corwin, J., Loury, M., \& Gilbert, A. (1995). Workplace, age, and sex as mediators of olfactory function: Data from the National Geographic Smell Survey. Journals of Gerontology: Series B: Psychological Sciences \& Social Sciences, 50B(4), 179-186.

Craik, F. I. M., \& Lockhart, R. S. (1972). Levels of processing: A framework for memory research. Journal of Verbal Learning and Verbal Behavior, 11, 671-684.

Crossley, M., D'Arcy, C., \& Rawson, N. S. B. (1997). Letter and category fluency in community-dwelling Canadian seniors: A comparison of normal participants to those with dementia of the Alzheimer or vascular type. Journal of Clinical and Experimental Neuropsychology, 19(1), 52-62.

Daniel, D. B., Pelotte, M., \& Lewis, J. (2000). Lack of sex differences on the Stroop Color Word Test across three age groups. Perceptual and Motor Skills, 90(2), 483-484.

Davatzikos, C., \& Resnick, S. M. (1998). Sex differences in anatomic measures of interhemispheric connectivity: Correlations with cognition in women but not men. Cerebral Cortex, 8, 635-640.

Davies, G., \& Robertson, N. (1993). Recognition memory for automobiles: A developmental study. Bulletin of the Psychonomic Society, 31(2), 103-106.

De Courten-Myers, G. (1999). The human cerebral cortex: Gender differences in structure and function. Journal of Neuropathology and Experimental Neurology, 58(3), 217-226.

de Groot, J. C., de Leeuw, F.-E., Oudkerk, M., van Gijn, J., Hofman, A., Jolles, J. et al. (2002). Periventricular cerebral white matter lesions predict rate of cognitive decline. Annals of Neurology, 52(3), 335341.

Deiber, M.-P., Wise, S. P., Honda, M., Catalan, M. J., Grafman, J., \& Hallett, M. (1997). Frontal and parietal networks for conditional motor learning: A positron emission tomography study. Journal of Neurophysiology, 78, 977-991.

Dekaban, A. S. (1978). Changes in brain weight during the span of human life: Relation of brain weights to body heights and body weights. Annals of Neurology, 4(4), 345-356.

Delgado, A. R., \& Prieto, G. (1996). Sex differences in visuospatial ability: Do performance factors play such an important role? Memory and Cognition, 24(4), 504-510. 
Desrosiers, J., Herbert, R., Bravo, G., \& Dutil, E. (1995). The Purdue Pegboard Test: Normative data for people aged 60 and older. Disability and Rehabilitation, 17, 217-224.

Diamond, R., \& Carey, S. (1986). Why faces are and are not special: An effect of expertise. Journal of Experimental Psychology: General, 115(2), 107-117.

Doty, R. L., Shaman, P., Appelbaum, S. L., Giberson, R., Siksorski, L., \& Rosenberg, L. (1984). Smell identification ability: Changes with age. Science, 226(4681), 1441-1443.

Drews, C. D., Yeargin-Allsopp, M., Decoufle, P., \& Murphy, C. C. (1995). Variation in the influence of selected sociodemographic risk factors for mental retardation. American Journal of Public Health, 85(3), 329-334.

Duff, S. J., \& Hampson, E. (2001). A sex difference on a novel spatial working memory task in humans. Brain and Cognition, 47(3), 470493.

Eagly, A. H. (1990). On the advantages of reporting sex comparisons. American Psychologist, 45, 560-562.

Eagly, A. H. (1994). On comparing women and men. Feminism and Psychology, 4(4), 513-522.

Eagly, A. H. (1995). The science and politics of comparing women and men. American Psychologist, 50(3), 145-158.

Eals, M., \& Silverman, I. (1994). The hunter-gatherer theory of spatial sex differences: Proximate factors mediating the female advantage in recall of object arrays. Ethology and Sociobiology, 15, 95-105.

Feingold, A. (1988). Cognitive gender differences are disappearing. American Psychologist, 43(2), 95-103.

Fitch, R. H., \& Bimonte, H. A. (2002). Hormones, brain, and behavior: Putative biological contributions to cognitive sex differences. In A. McGillicuddy-De Lisi \& R. De Lisi (Eds.), Biology, society, and behavior. The development of sex differences in cognition (pp. 5591). Westport, CT: Ablex Publishing.

Freire, A., \& Lee, K. (2001). Face recognition in 4- to 7-year olds: Processing of configural, featural, and paraphernalia information. Journal of Experimental Child Psychology, 80, 347-371.

Galea, L. A. M., \& Kimura, D. (1993). Sex differences in route learning. Personality and Individual Differences, 14(1), 53-65.

Geer, J. H., \& McGlone, M. S. (1990). Sex differences in memory for erotica. Cognition and Emotion, 4(1), 71-78. 
Geschwind, N., \& Galaburda, A. M. (1987). Cerebral lateralization: Biological mechanisms, associations, and pathology. Cambridge, MA: MIT Press.

Gladue, B. A., Beatty, W. W., Larson, J., \& Staton, R. D. (1990). Sexual orientation and spatial ability in men and women. Psychobiology, 18(1), 101-108.

Goldstein, A. G., \& Chance, J. E. (1970). Visual recognition memory for complex configurations. Perception and Psychophysics, 9(2B), 237241.

Goldstein, D., Haldane, D., \& Mitchell, C. (1990). Sex differences in visual-spatial ability: The role of performance factors. Memory and Cognition, 18(5), 546-550.

Gur, R. C., Gur, R. E., Obrist, W. D., Hungerbuhler, J. P., Younkin, D., Rosen, A. D. et al. (1982). Sex and handedness differences in cerebral blood flow during rest and cognitive activity. Science, 217(4560), 651-661.

Gur, R. E., \& Gur, R. C. (1990). Gender differences in regional cerebral blood flow. Schizophrenia Bulletin, 16(2), 247-254.

Hall, J. A. Y., \& Kimura, D. (1995). Sexual orientation and performance on sexually dimorphic motor tasks. Archives of Sexual Behavior, 24(4), 395-407.

Halpern, D. F. (1997). Sex differences in intelligence: Implications for education. American Psychologist, 52, 1091-1102.

Halpern, D. F. (2000). Sex differences in cognitive abilities (3 ed.). Mahwah, NJ: Lawrence Erlbaum Associates.

Halpern, D. F., Haviland, M. G., \& Killian, C. D. (1998). Handedness and sex differences in intelligence: Evidence from the medical college admission test. Brain and Cognition, 38, 87-101.

Halpern, D. F., \& Ikier, S. (2002). Causes, correlates, and caveats: Understanding the development of sex differences in cognition. In A. McGillicuddy-De Lisi \& R. De Lisi (Eds.), Biology, society, and behavior. The development of sex differences in cognition (pp. 3-19). Westport, CT: Ablex Publishing.

Halpern, D. F., \& Tan, U. (2001). Stereotypes and steroids: Using a psychobiosocial model to understand cognitive sex differences. Brain and Cognition, 45, 392-414.

Hasher, L., Zacks, R. T., \& May, C. P. (1999). Inhibitory control, corcadian arousal, and age. In D. Gopher \& A. Koriat (Eds.), Attention and performance XVII: Cognitive regulation of performance: Interaction 
of theory and application (pp. 653-675). Cambridge, MA: The MIT Press.

Hassing, L., Wahlin, Å., \& Bäckman, L. (1998). Minimal influence of age, education, and gender on episodic memory functioning in very old age: A population based study. Archives of Gerontology and Geriatrics, 27, 75-87.

Herlitz, A., Airaksinen, E., \& Nordström, E. (1999). Sex differences in episodic memory: The impact of verbal and visuospatial ability. Neuropsychology, 13(4), 590-597.

Herlitz, A., Nilsson, L.-G., \& Bäckman, L. (1997). Gender differences in episodic memory. Memory and Cognition, 25(6), 801-811.

Hertzog, C., Vernon, M. C., \& Rympa, B. (1993). Age differences in mental rotation task performance: The influence of speed/accuracy tradeoffs. Journals of Gerontology, 48(3), 150-156.

Hill, R. D., Grut, M., Wahlin, Å., Herlitz, A., Winblad, B., \& Bäckman, L. (1995). Predicting memory performance in optimally healthy very old adults. Journal of Mental Health and Aging, 1(1), 57-67.

Hines, M., Chiu, L., McAdams, L. A., Bentler, P. M., \& Lipcamon, J. (1992). Cognition and the corpus callosum: Verbal fluency, visuospatial ability, and language lateralization related to midsagittal surface areas of callosal subregions. Behavioral Neuroscience, 106(1), 3-14.

Hines, M., \& Collaer, M. L. (1993). Gonadal hormones and sexual differentiation of human behavior: Developments from research on endocrine syndromes and studies of brain structure. Annual Review of Sex Research, 4, 1-48.

Hiscock, M., Perachio, N., \& Inch, R. (2001). Is there a sex difference in human laterality? IV. An exhaustive survey of dual-task interference studies from six neuropsychology journals. Journal of Clinical and Experimental Neuropsychology, 23(2), 137-148.

Holding, C. S., \& Holding, D. H. (1989). Acquisition of route network knowledge by males and females. Journal of General Psychology, 116(1), 29-41.

Hyde, J. S., Fennema, E., \& Lamon, S. J. (1990). Gender differences in mathematics performance: A meta-analysis. Psychological Bulletin, 107(2), 139-155.

Hyde, J. S., \& Linn, M. C. (1988). Gender differences in verbal ability: A meta-analysis. Psychological Bulletin, 104(1), 53-69.

Hyde, J. S., \& McKinley, N. M. (1997). Gender differences in cognition: 
Results from meta-analyses. In P. J. Caplan \& M. Crawford \& J. S. Hyde \& J. T. E. Richardson (Eds.), Gender differences in cognition. Counterpoints: Cognition, memory, and language (pp. 30-51). London: Oxford University Press.

Ingram, D. (1975). Motor asymmetries in young children. Neuropsychologia, 13(1), 95-102.

James, T. W., \& Kimura, D. (1997). Sex differences in remembering the locations of objects in an array: Location-shifts versus locationexchanges. Evolution and Human Behavior, 18, 155-163.

Janowsky, J. S., Chaves, B., \& Orwoll, E. (2000). Sex steroids modify working memory. Journal of Cognitive Neuroscience, 12(3), 407414.

Joy, S., Fein, D., Kaplan, E., \& Freedman, M. (2000). Speed and memory in WAIS-R-NI digit symbol performance among healthy older adults. Journal of the International Neuropsychological Society, 6, 770-780.

Kempler, D., Teng, E. L., Dick, M., Taussig, I. M., \& Davis, D. S. (1998). The effects of age, education, and ethnicity on verbal fluency. Journal of the International Neuropsychological Society, 4, 531-538.

Kimura, D. (1996). Sex, sexual orientation and sex hormones influence human cognitive function. Current Opinion in Neurobiology, 6, 259263.

Kimura, D. (1999). Sex and cognition. Cambridge, MA: The MIT Press.

Kimura, D., \& Vanderwolf, C. H. (1970). The relation between hand preference and the performance of individual finger movements by left and right hands. Brain, 93(4), 769-774.

King, D. A., \& Caine, E. D. (1990). Depression. In J. L. Cummings (Ed.), Subcortical dementia (pp. 218-230). London: Oxford University Press.

Kramer, J. H., Delis, D. C., Kaplan, E., O’Donell, L., \& Prifitera, A. (1997). Developmental sex differences in verbal learning. Neuropsychology, 11(4), 577-584.

La Voie, D., \& Light, L. L. (1994). Adult age differences in repetition priming: A meta-analysis. Psychology and Aging, 9(4), 539-553.

Larrabee, G. J., \& Crook, T. H. (1993). Do men show more rapid agerelated decline in simulated every day verbal memory than do women? Psychology and Aging, 8(1), 68-71.

Law, D. J., Pellegrino, J. W., \& Hunt, E. B. (1993). Comparing the tortoise and the hare: Gender differences and experience in dynamic spatial 
reasoning tasks. Psychological Science, 4(1), 35-40.

Lawton, C. A. (1996). Strategies for indoor wayfinding: The role of orientation. Journal of Environmental Psychology, 16, 137-145.

Lawton, C. A., Charleston, S. I., \& Zieles, A. S. (1996). Individual- and gender-related differences in indoor wayfinding. Environment and Behavior, 28(2), 204-219.

Lawton, C. A., \& Kallai, J. (2002). Gender differences in wayfinding strategies and anxiety about wayfinding: A cross-cultural comparison. Sex Roles, 47(9/10), 389-401.

Lawton, C. A., \& Morrin, K. A. (1999). Gender differences in pointing accuracy in computer-simulated 3D mazes. Sex Roles, 40(1/2), 7392.

Lehrner, J. P. (1993). Gender differences in long-term odor recognition memory: Verbal versus sensory influences and the consistency of label use. Chemical Senses, 18(1), 17-26.

Levine, S. C., Huttelocher, J., Taylor, A., \& Langrock, A. (1999). Early sex differences in spatial skills. Developmental Psychology, 35(4), 940949.

Levy, J. (1976). Cerebral lateralization and spatial ability. Behavior Genetics, 6(2), 171-188.

Levy, J., \& Nagylaki, T. (1972). A model for the genetics of handedness. Genetics, 72, 117-128.

Light, L. L., \& La Voie, D. (1993). Direct and indirect measures of memory in old age. In P. Graf \& M. E. J. Masson (Eds.), Implicit memory: New directions in cognition, development, and neuropsychology (pp. 207-230). Hillsdale, NJ, England: Lawrence Erlbaum Associates, Inc.

Linn, M. C., \& Petersen, A. C. (1985). Emergence and characterization of sex differences in spatial ability: A meta-analysis. Child Development, 56, 1479-1498.

MacArthur, R. (1967). Sex differences in field dependence for the Eskimo. International Journal of Psychology, 2, 139-140.

Maccoby, E. E., \& Jacklin, C. N. (1974). The psychology of sex differences. Stanford, CA: Stanford University Press.

Majeres, R. L. (1983). Sex differences in symbol-digit substitution and speeded matching. Intelligence, 7(4), 313-327.

Mann, V. A., Sasanuma, S., Sakuma, N., \& Masaki, S. (1990). Sex differences in cognitive abilities: A cross-cultural perspective. Neuropsychologia, 28(10), 1063-1077. 
Masters, M. S., \& Sanders, B. (1993). Is the gender difference in mental rotation disappearing? Behavior Genetics, 23(4), 337-341.

McBurney, D. H., Gaulin, S. J. C., Devineni, T., \& Adams, C. (1997). Superior spatial memory of women: Stronger evidence for the gathering hypothesis. Evolution and Human Behavior, 18, 165-174.

McCormick, C. M., \& Witelson, S. F. (1991). A cognitive profile of homosexual men compared to heterosexual men and women. Psychoneuroendocrinology, 16(6), 459-473.

McEwen, B. S., Alves, S. E., Bulloch, K., \& Weiland, N. (1997). Ovarian steroids and the brain: Implications for cognitive agin. Neurology, 48(5, Supp1 7), S8-S15.

McGlone, J. (1980). Sex differences in human brain asymmetry: A critical survey. Behavioral and Brain Sciences, 3(2), 215-263.

McKelvie, S. J. (1981). Sex differences in memory for faces. The Journal of Psychology, 107, 109-125.

McKelvie, S. J., Standing, L., St. Jean, D., \& Law, J. (1993). Gender differences in recognition memory for faces and cars: Evidence for the interest hypothesis. Bulletin of the Psychonomic Society, 31(5), 447-448.

Meissner, C. A., \& Brigham, J. C. (2001). Thirty years of investigating the own-race bias in memory for faces: A meta-analytic review. Psychology, Public Policy, and Law, 7(1), 3-35.

Miles, T. R., Haslum, M. N., \& Wheeler, T. J. (1998). Gender ratio in dyslexia. Annals of Dyslexia, 48, 27-55.

Miller, G. A. (1956). The magical number seven, plus or minus two: Some limits on our capacity for processing information. The Psychological Review, 63(2), 81-97.

Mitchell, D. B. (1989). How many memory systems? Evidence from aging. Journal of Experimental Psychology: Learning, Memory and Cognition, 15(1), 31-49.

Munroe, R. L., \& Munroe, R. H. (1971). Effect of environmental experience on spatial ability in an East African society. Journal of Social Psychology, 83(1), 15-22.

Nicholson, K. G., \& Kimura, D. (1996). Sex differences for speech and manual skill. Perceptual and Motor Skills, 82(1), 3-13.

Nilsson, L.-G., Bäckman, L., Erngrund, K., Nyberg, L., Adolfsson, R., Bucht, G. et al. (1997). The Betula prospective cohort study: Memory, health and aging. Aging, Neuropsychology, and Cognition, 4(1), 1-32. 
Nyberg, L., \& Cabeza, R. (2000). Brain imaging of memory. In E. Tulving \& F. I. M. Craik (Eds.), The Oxford handbook of memory (pp. 501519). Oxford: Oxford University Press.

Nyberg, L., Habib, R., \& Herlitz, A. (2000). Brain activation during episodic memory retrieval: Sex differences. Acta Psychologica, 105, 181-194.

Nyberg, L., \& Tulving, E. (1996). Classifying human long-term memory: Evidence from converging dissociations. European Journal of Cognitive Psychology, 8(2), 163-183.

Öberg, C., Larsson, M., \& Bäckman, L. (2002). Differential sex effects in olfactory functioning: The role of verbal processing. Journal of the International Neuropsychological Society, 8, 691-698.

Pakkenberg, B., \& Gundersen, H. J. G. (1997). Neocortical neuron number in humans: Effect of sex and age. The Journal of Comparative Neurology, 384, 312-320.

Pasquier, F., Lebert, F., Grymonprez, L., \& Petit, H. (1995). Verbal fluency in dementia of frontal lobe type and dementia of Alzheimer type. Journal of Neurology, Neurosurgery and Psychiatry, 58(1), 81-84.

Passe, T. J., Rajagopalan, P., Tupler, L. A., Byrum, C. E., MacFall, J. R., \& Krishnan, K. R. R. (1997). Age and sex effects on brain morphology. Progress in Neuro-Psychopharmacology and Biological Psychiatry, 21, 1231-1237.

Pendleton, M. G., Heaton, R. K., Lehman, R. A., \& Hulihan, D. M. (1982). Diagnostic utility of the Thurston Word Fluency Test in neuropsychological evaluations. Journal of Clinical Neuropsychology, 4(4), 307-317.

Peretti, C.-S., Danion, J.-M., Gierski, F., \& Grangé, D. (2002). Cognitive skill learning and aging: A component process analysis. Archives of Clinical Neuropsychology, 17, 445-459.

Peters, M., Servos, P., \& Day, R. (1990). Marked sex differences on a fine motor skill task disappear when finger size is used as covariate. Journal of Applied Psychology, 75(1), 87-90.

Peterson, L. R., \& Peterson, M. J. (1959). Short-term retention of individual verbal items. Journal of Experimental Psychology, 58, 193-198.

Portin, R., Saarijärvi, S., Joukamaa, M., \& Salokangas, R. K. R. (1995). Education, gender and cognitive performance in a 62-year-old normal population: Results from the Turva project. Psychological Medicine, 25, 1295-1298. 
Raichle, M. E. (1994). Images of the mind: Studies with modern imaging techniques. Annual Review of Psychology, 45, 333-356.

Resnick, S. M. (1993). Sex differences in mental rotations: An effect of time limits? Brain and Cognition, 21(1), 71-79.

Robert, M., \& Harel, F. (1996). The gender difference in orienting liquid surfaces and plumb-lines: Its robustness, its correlates, and the associated knowledge of simple physics. Canadian Journal of Experimental Psychology, 50(3), 280-314.

Roediger, H. L. (1990). Implicit memory: Retention without remembering. American Psychologist, 45(9), 1043-1056.

Ruff, R. M., Light, R. H., \& Quayhagen, M. (1988). Selective reminding tests: A normative study of verbal learning in adults. Journal of Clinical and Experimental Neuropsychology, 11(4), 539-550.

Salthouse, T. A. (1998). Independence of age-related influences on cognitive abilities across the life span. Developmental Psychology, 34(5), 851-864.

Sanders, G., Sjodin, M., \& de Chastelaine, M. (2002). On the elusive nature of sex differences in cognition: Hormonal influences contributing to within-sex variation. Archives of Sexual Behavior, 31(1), 145-152.

Sanders, G., \& Wright, M. (1997). Sexual orientation differences in cerebral asymmetry and in the performance of sexually dimorphic cognitive and motor tasks. Archives of Sexual Behavior, 26(5), 463480.

Saucier, D. M., Elias, L. J., \& Nylen, K. (2002). Are colours special? An examination of the female advantage for speeded colour naming. Personality and Individual Differences, 32, 27-35.

Saucier, D. M., Green, S. M., Leason, J., MacFadden, A., Bell, S., \& Elias, L. J. (2002). Are sex differences in navigation caused by sexually dimorphic strategies or by differences in the ability to use the strategies? Behavioral Neuroscience, 116(3), 403-410.

Schacter, D. L. (1987). Implicit memory: History and current status. Journal of Experimental Psychology: Learning, Memory \& Cognition, 13(3), 501-518.

Schacter, D. L., Wagner, A. D., \& Buckner, R. L. (2000). Memory systems of 1999. In E. Tulving \& F. I. M. Craik (Eds.), The Oxford handbook of memory (pp. 627-643). Oxford: Oxford University Press.

Shaywitz, B. A., Shaywitz, S. E., Pugh, K. R., Constable, R. T., Skudlarski, P., Fulbright, R. K. et al. (1995). Sex differences in the functional organization of the brain for language. Nature, 373, 607-609. 
Silverman, I., \& Eals, M. (1992). Sex differences in spatial abilities: Evolutionary theory and data. In J. H. Barkow \& L. Cosmides \& J. Tooby (Eds.), The adapted mind: Evolutionary psychology and the generation of culture. New York: Oxford University Press.

Silverman, I., Phillips, K., \& Silverman, L. K. (1996). Homogeneity of effect sizes for sex across spatial tests and cultures: Implications for hormonal theories. Brain and Cognition, 31, 90-94.

Small, S. A., Tsai, W. T., DeLaPaz, R., Mayeux, R., \& Stern, Y. (2002). Imaging hippocampal function across the human life span: Is memory decline normal or not? Annals of Neurology, 51(3), 290295.

Spreen, O., \& Strauss, E. (1998). A compendium of neuropsychological tests: Administration, norms and commentary (2 ed.). New York: Oxford University Press.

Squire, L. R., \& Kandel, E. R. (1999). Memory: From mind to molecules. New York: Scientific American Library.

Steinmetz, H., Staiger, J. F., Schlaug, G., Huang, Y., \& Janke, L. (1995). Corpus callosum and brain volume in women and men. Neuroreport: An International Journal for the Rapid Communication of Research in Neuroscience, 6(7), 1002-1004.

Strickland, T. L., D'Elia, L. F., James, R., \& Stein, R. (1997). Stroop colorword performance of African Americans. Clinical Neuropsychologist, 11(1), 87-90.

Swaab, D. F., Zhou, J.-N., Fodor, M., \& Hofman, M. A. (1997). Sexual differentiation of the human hypothalamus: Differences according to sex, sexual orientation, and transsexuality. In L. Ellis \& L. Ebertz (Eds.), Sexual orientation: Toward biological understanding (pp. 129-150). Westport, CT: Praeger Publishers/Greenwood Publishing Group, Inc.

Temple, C. M., \& Cornish, K. M. (1993). Recognition memory for words and faces in schoolchildren: A female advantage for words. British Journal of Developmental Psychology, 11, 421-426.

Tomer, R., \& Levin, B. E. (1993). Differential effects of aging on two verbal fluency tasks. Perceptual and Motor Skills, 76(2), 465-466.

Trenerry, M. R., Jack, C. R., Cascino, G. D., Sharbrough, F. W., \& Ivnik, R. J. (1996). Sex differences in the relationship between visual memory and MRI hippocampal volumes. Neuropsychology, 10(3), 343-351.

Troyer, A. K., Moscovitch, M., Winocur, G., Leach, L., \& Freedman, M. 
(1998). Clustering and switching on verbal fluency tests in Alzheimer's and Parkinson's disease. Journal of the International Neuropsychological Society, 4, 137-143.

Tulving, E. (1972). Episodic and semantic memory. In E. Tulving \& W. Donaldson (Eds.), Organization of memory (pp. 381-403). New York: Academic Press, Inc.

Tulving, E. (1983). Elements of episodic memory. Oxford: Clarendon Press.

Tulving, E. (1985). How many memory systems are there? American Psychologist, 40(4), 385-398.

Tulving, E. (1993). What is episodic memory? Current Directions in Psychological Science, 2(3), 67-70.

Tulving, E. (1999). On the uniqueness of episodic memory. In L.-G. Nilsson \& H. J. Markowitsch (Eds.), Cognitive neuroscience of memory (pp. 11-43). Kirkland, WA: Hogrefe \& Huber Publishers.

Tulving, E. (2002). Episodic memory: From mind to brain. Annual Review of Psychology, 53, 1-25.

Tulving, E., \& Schacter, D. L. (1990). Priming and human memory systems. Science, 247(4940), 301-306.

Usall, J., Araya, S., Ochoa, S., Busquets, E., Gost, A., \& Márques, M. (2001). Gender differences in a sample of schizophrenic outpatients. Comprehensive Psychiatry, 42(4), 301-305.

Vandenberg, S. G. (1971). A test of three-dimensional spatial visualization based on the Shephard-Metzler "mental rotation" study. Boulder: University of Colorado.

Verhaeghen, P., Marcoen, A., \& Goossens, L. (1993). Facts and fiction about memory and aging: A quantitative integration of research findings. Journals of Gerontology, 48(4), 157-171.

Vokey, J. R., \& Read, J. D. (1988). Typicality, familiarity and the recognition of male and female faces. Canadian Journal of Psychology, 42(4), 489-495.

Voyer, D., Voyer, S., \& Bryden, M. P. (1995). Magnitude of sex differences in spatial abilities: A meta-analysis and consideration of critical variables. Psychological Bulletin, 117(2), 250-270.

Wahlin, Å., Bäckman, L., Mäntylä, T., Herlitz, A., Viitanen, M., \& Winblad, B. (1993). Prior knowledge and face recognition in a community-based sample of healthy, very old adults. Journal of Gerontology, 48(2), 54-61.

Watson, N. V., \& Kimura, D. (1991). Nontrivial sex differences in 
throwing and intercepting: Relation to psychometrically defined spatial functions. Personality and Individual Differences, 12(5), 375385.

Wechsler, D. (1981). Manual for the Wechsler Adult Intelligence Scale Revised. New York: Psychological Corporation.

Westergaard, G. C., Liv, C., Haynie, M. K., \& Suomi, S. J. (2000). A comparative study of aimed throwing by monkeys and humans. Neuropsychologia, 38, 1511-1517.

Wood, F. B., Flowers, D. L., \& Naylor, C. E. (1991). Cerebral laterality in functional neuroimaging. In F. L. Kitterle (Ed.), Cerebral laterality: Theory and research: The Toledo symposium (pp. 103-115). Hillsdale, NJ, England: Lawrence Erlbaum Associates.

Wright, M. J., Smith, G. A., Geffen, G. M., Geffen, L. B., \& Martin, N. G. (2000). Genetic influence on the variance in coincidence timing and its covariance with IQ: A twin study. Intelligence, 28(4), 239-250.

Xu, J., Kobayashi, S., Yamaguchi, S., Iijima, K., Okada, K., \& Yamashita, K. (2000). Gender effects on age-related changes in brain structure. American Journal of Neuroradiology, 21, 112-118.

Zelinski, E. M., Gilewski, M. J., \& Schaie, K. W. (1993). Individual differences in cross-sectional and 3-year longitudinal memory performance across the adult life span. Psychology and Aging, 8(2), 176-186. 